\title{
Stroke: roles of B vitamins, homocysteine and antioxidants
}

\author{
Concepción Sánchez-Moreno ${ }^{1 *}$, Antonio Jiménez-Escrig ${ }^{2}$ and Antonio Martín ${ }^{3}$ \\ ${ }^{1}$ Department of Plant Foods Science and Technology, Instituto del Frío, CSIC, Madrid, Spain \\ ${ }^{2}$ Department of Metabolism and Nutrition, Instituto del Frío, CSIC, Madrid, Spain \\ ${ }^{3}$ Nutrition and Neurocognition Laboratory, Jean Mayer USDA-Human Nutrition Research Center \\ on Aging at Tufts University, Boston, MA, USA (former address)
}

\begin{abstract}
In the present review concerning stroke, we evaluate the roles of B vitamins, homocysteine and antioxidant vitamins. Stroke is a leading cause of death in developed countries. However, current therapeutic strategies for stroke have been largely unsuccessful. Several studies have reported important benefits on reducing the risk of stroke and improving the post-stroke-associated functional declines in patients who ate foods rich in micronutrients, including $\mathrm{B}$ vitamins and antioxidant vitamins $\mathrm{E}$ and $\mathrm{C}$. Folic acid, vitamin $\mathrm{B}_{6}$ and vitamin $\mathrm{B}_{12}$ are all cofactors in homocysteine metabolism. Growing interest has been paid to hyperhomocysteinaemia as a risk factor for CVD. Hyperhomocysteinaemia has been linked to inadequate intake of vitamins, particularly to B-group vitamins and therefore may be amenable to nutritional intervention. Hence, poor dietary intake of folate, vitamin $\mathrm{B}_{6}$ and vitamin $\mathrm{B}_{12}$ are associated with increased risk of stroke. Elevated consumption of fruits and vegetables appears to protect against stroke. Antioxidant nutrients have important roles in cell function and have been implicated in processes associated with ageing, including vascular, inflammatory and neurological damage. Plasma vitamin $\mathrm{E}$ and $\mathrm{C}$ concentrations may serve as a biological marker of lifestyle or other factors associated with reduced stroke risk and may be useful in identifying those at high risk of stroke. After reviewing the observational and intervention studies, there is an incomplete understanding of mechanisms and some conflicting findings; therefore the available evidence is insufficient to recommend the routine use of $\mathrm{B}$ vitamins, vitamin $\mathrm{E}$ and vitamin $\mathrm{C}$ for the prevention of stroke. A better understanding of mechanisms, along with well-designed controlled clinical trials will allow further progress in this area.
\end{abstract}

B vitamins: Homocysteine: Antioxidant vitamins E and C: Oxidative stress: Stroke

\section{Introduction}

Stroke is a leading cause of death in developed countries. However, current therapeutic strategies for stroke have been largely unsuccessful. It is estimated that stroke is responsible for $9.5 \%$ of all deaths and 5.1 million of the 16.7 million CVD deaths ${ }^{(1)}$. Furthermore, nearly one-third of stroke survivors have some degree of dementia after stroke. Of patients who had ischaemic stroke, $32 \%$ had dementia based on comprehensive neurological and psychological testing, clinical mental status interviews, MRI scans and detailed histories collected ${ }^{(2-4)}$. Importantly, dementia is more common in stroke patients who are older, smoke and have lower levels of education ${ }^{(2)}$. In addition, vascular dementia often coexists with Alzheimer's disease, and the presence of Alzheimer's disease may predispose one to the development of vascular dementia. In fact, the $5 \%$ prevalence in cognitive impairment that occurs in the elderly over the age of 65 years increases sharply after ischaemic stroke, up to $38 \%$. Cognitive impairment is associated with death or disability at 4 years after a stroke ${ }^{(5)}$. But vascular dementia, which is the second most important cause of cognitive impairment and dementia associated with ageing in the USA, is the most preventable form affecting the elderly.

The realisation that brain ischaemia elicits more robust brain damage when nutritional status is poorer provides a fertile ground for the discovery of novel therapeutic agents and nutritional intervention for stroke. Deficiency of B vitamins and antioxidant vitamins $\mathrm{E}$ and/or $\mathrm{C}$ appears to increase cognitive impairment in stroke patients ${ }^{(6-8)}$. Better understanding of the role that specific nutrients play on vasculature and brain's cell response in stroke patients may

Abbreviations: Hcy, homocysteine; MCP-1, monocyte chemoattractant protein-1.

* Corresponding author: Dr C. Sánchez-Moreno, fax + 3491 5493627, email csanchezm@if.csic.es 
be relevant to reduce the incidence of cognitive impairment and dementia associated with stroke. Interestingly, B vitamins play critical roles in cell function ${ }^{(9)}$. For example, folate in the 5-methyltetrahydrofolate form is a co-substrate required by methionine synthase to convert homocysteine (Hcy) to methionine; consequently, Hcy accumulates when folate is low ${ }^{(10,11)}$. High Hcy is strongly associated with atherosclerotic vascular disease and stroke ${ }^{(12)}$. Furthermore, several surveys have shown positive correlation between low folate levels and dementia ${ }^{(13)} . \mathrm{B}_{12}$ is important in maintaining the nervous system where it plays a vital role in the metabolism of fatty acids essential to maintain myelin ${ }^{(14)}$. Vitamin $B_{12}$ is also required for methionine synthesis from $\mathrm{Hcy}^{(15)}$. Prolonged $\mathrm{B}_{12}$ deficiency can lead to nerve degeneration and irreversible neurological damage ${ }^{(16)}$. Vitamin $\mathrm{B}_{6}$ is needed for the synthesis of neurotransmitters such as serotonin and dopamine. A deficiency of vitamin $\mathrm{B}_{6}$ may also contribute to increase levels of Hcy. Fig. 1 shows the biochemical pathways of Hcy metabolism with the roles of folate, $\mathrm{B}_{6}$ and $\mathrm{B}_{12}{ }^{(15)}$.

Several reports have suggested a relevant effect of dietary antioxidants, including vitamins $\mathrm{E}$ and $\mathrm{C}$, on stroke prevention $^{(17-19)}$. Ascorbic acid administration to a primate model after focal cerebral ischaemia significantly reduced the size of the infarct ${ }^{(20)}$. Furthermore, data from the Third National Health and Nutrition Examination Survey (NHANES III) indicate a biological interaction between ascorbic acid and alcohol and suggest that higher intake of ascorbic acid may be associated with a decreased vascular risk among drinkers ${ }^{(21)}$. Among 87245 US female registered nurses, aged 34-59 years, higher antioxidant vitamin consumption was associated with a reduced risk of ischaemic stroke ${ }^{(19)}$. In addition, high consumption of cruciferous vegetables and citrus fruit juice reduced the risk of stroke ${ }^{(22)}$. From a 25-year follow-up study of middleaged men who participated in the Framingham Cardiovascular Study ${ }^{(23)}$ investigators re-examined 832 men, aged 45-65 years, who had been free of CVD when they began the Framingham Study in 1969 and observed an inverse association between fruit and vegetable intake and the development of stroke.

A study of the intake of antioxidants and the risk of stroke provides tantalising, albeit preliminary, evidence that vitamin $\mathrm{E}$ might be of value in reducing the risk of stroke $^{(24)}$. An inverse association was seen between death from stroke and vitamin E intake from food, which reflected a continued association from the lowest to the highest intake categories, thus supporting a protective role for vitamin E

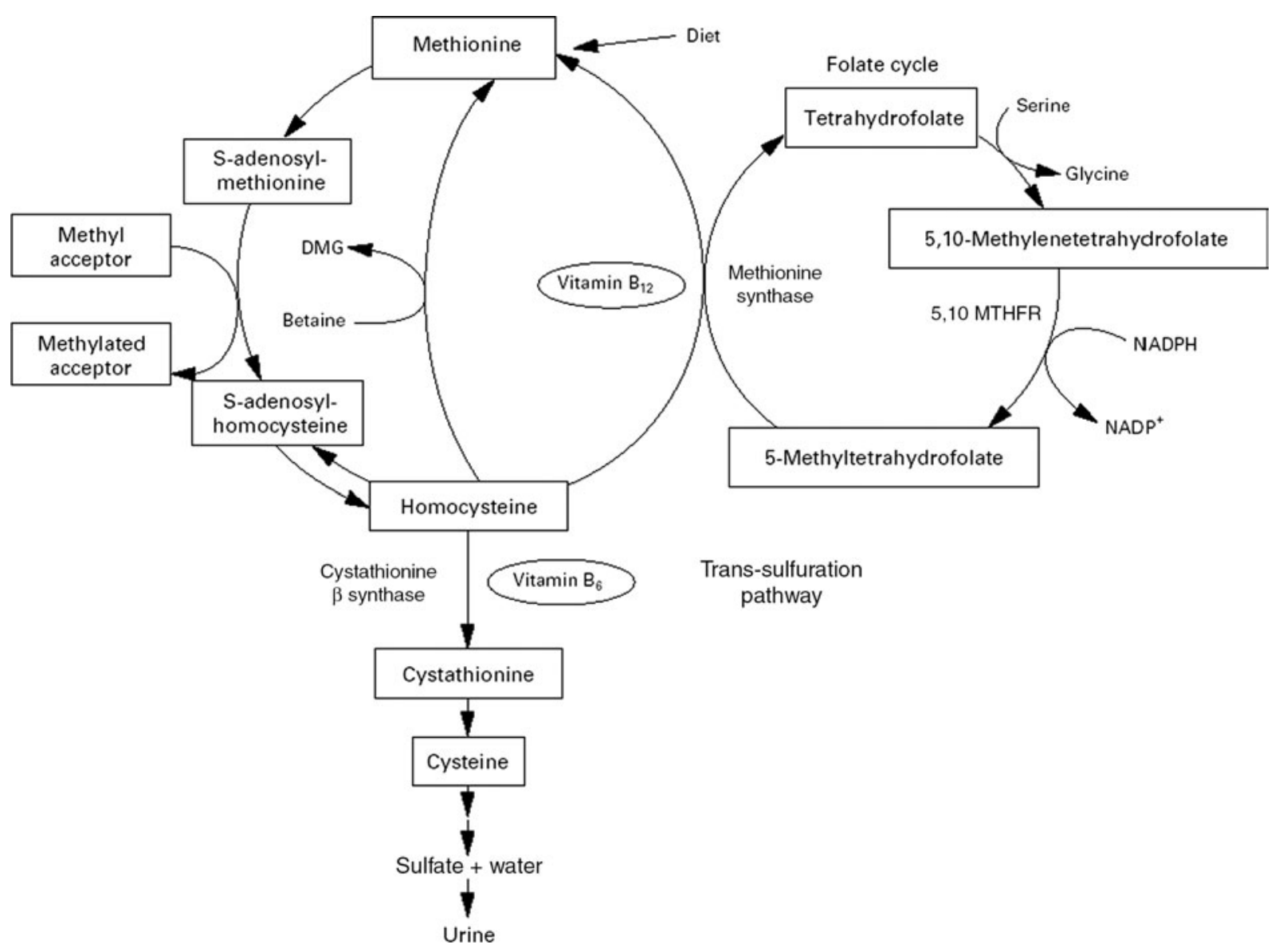

Fig. 1. Pathways for the metabolism of homocysteine. Normal trans-sulfuration requires cystathionine $\beta$ synthase with vitamin $B_{6}$ as cofactor. Remethylation requires 5,10-methylenetetrahydrofolate reductase (5,10-MTHFR) and methionine synthase. The latter requires folate as co-substrate and vitamin $\mathrm{B}_{12}$ (cobalamin) as cofactor. An alternative remethylation pathway also exists using the cobalamin-independent betaine-homocysteine methyltransferase ${ }^{(15)}$. DMG, dimethylglycine. 
or other antioxidant vitamins ${ }^{(24)}$. Previous studies reported a significant reduction in the incidence of ischaemic events in patients taking vitamin $\mathrm{E}$ plus aspirin compared with patients taking only aspirin ${ }^{(25-27)}$. Vitamin $\mathrm{C}$ status may be a determinant of cognitive function in elderly people through its effect on atherogenesis. Low consumption of vitamin $\mathrm{C}$ as well as low plasma levels were associated with a greater risk of cognitive disorders in a 20-year follow-up study ${ }^{(6)}$.

As the number of older people grows rapidly worldwide, along with the fact that elderly people are also living longer, the risk of stroke and stroke-associated dementia - which is one of the most common causes of cognitive impairment is increasingly becoming an important public health problem. Since nutrition plays a role in the ageing process, relatively simple and inexpensive treatments involving dietary intervention and vitamin supplementation may reduce the risk of stroke and ameliorate the neurological and neurocognitive impairments associated with stroke. Therefore, in the present review we will examine the potential role that nutritional status - specifically $B$ vitamins and antioxidants - plays in reducing the deleterious effects associated with stroke. Tables 1 and 2 show a summary of some of the observational and intervention studies in the literature regarding $\mathrm{B}$ vitamins, Hcy and stroke, and antioxidant vitamins $\mathrm{E}$ and $\mathrm{C}$ and stroke, respectively.

\section{Nutrition and stroke}

The dietary guidelines of the American Heart Association include specific recommendations tailored to an individual's risk of heart disease and stroke that are based on an analysis of hundreds of studies ${ }^{(28)}$. This recommended diet provides a generous amount of micronutrients essential for good health; however, a very small percentage of the population follows it. In spite of these recommendations, several studies have indicated that few of us eat well, and nutritional deficiencies or low nutrient levels in tissues are very common. For example, in a study of 402 elderly Europeans living at home, the nutrient content of their diet was found to be low: folate intake was low in $100 \%$ of those studied, $\mathrm{Zn}$ in $87 \%$, vitamin $\mathrm{B}_{6}$ in $83 \%$ and vitamin $\mathrm{D}$ in $62 \%(29)$ A cross-sectional study looking into the association of dietary $\beta$-carotene, vitamin $C$ and vitamin $E$ with peripheral arterial disease was performed in Rotterdam, the Netherlands, between 1990 and 1993 in 4367 subjects aged 55-94 years. Diet was assessed with a FFQ. In multivariateadjusted logistic regression analyses, vitamin $\mathrm{C}$ and $\mathrm{E}$ intake was significantly inversely associated with peripheral arterial disease $^{(30)}$.

Brussaard et al. ${ }^{(31)}$ assessed the adequacy of folate intake and status among adults in the Netherlands. They concluded that the folate intake among adult men and women was adequate in view of recommended daily intakes. However, the folate intake among women did not meet the recommendation for those who want to become pregnant. According to criteria derived from Hcy metabolism as related to CVD, folate status may not be adequate in $60-79 \%$ of adult age-sex groups. However, the percentage of adults with low folate status is going to vary widely between countries dependent on folic acid fortification and other dietary considerations.

Folate, riboflavin, vitamin $\mathrm{B}_{6}$ and vitamin $\mathrm{B}_{12}$ are essential in Hcy metabolism, and elevated plasma Hcy concentration is associated with an increased risk of CVD. In a random sample of 2435 men and women, aged 20-65 years, who were examined between 1993 and 1996, B vitamins were inversely related to the plasma Hcy concentration; however, only folate intake remained inversely associated with the plasma Hcy concentration following multivariate-adjusted logistic regression analyses ${ }^{(32)}$. Data consistently indicate that folic acid supplementation in the form of vitamin tablets is the most effective strategy to lower mild-to-moderately elevated $\mathrm{Hcy}^{(33)}$. However, in folic acid-fortified populations, vitamin $B_{12}$ status emerges as the most important nutritionally modifiable determinant of Hcy levels ${ }^{(34,35)}$. Steps to either reduce the prevalence of vitamin $B_{12}$ deficiency or to identify and treat individuals with vitamin $\mathrm{B}_{12}$ deficiency could further reduce the prevalence of hyperhomocysteinaemia ${ }^{(35)}$

To assess how changes in Hcy levels may influence poststroke response, Howard et al. ${ }^{(36)}$ used a multicentre design study to examine changes on Hcy during the 2 weeks after an incident stroke. They collected blood samples from fifty-one subjects at days $1,3,5,7$, and between 10 and $14 \mathrm{~d}$ after the stroke. The estimated mean Hcy level at baseline was 11.3 (SEM 0.5) $\mu \mathrm{mol} / \mathrm{l}$, which increased consistently to 12.0 (SEM $0.05), 12.4$ (SEM 0.5), 13.3 (SEM 0.5) and 13.7 (SEM 0.7) $\mu \mathrm{mol} / 1$ at days $3,5,7$ and $10-14$, respectively. The magnitude of the changes in Hcy was not affected by age, smoking status, alcohol use, history of hypertension or diabetes, or Rankin scale score. This study would be strengthened by an assessment of Hcy taken during the convalescent period. With this additional assessment, the authors would have been able to assess the proportion of the change between the acute and convalescent period. These observations suggest that the relevance and clinical interpretation of Hcy after stroke require an adjustment in time. Much of the evidence of the association of Hcy and stroke risk is based on a comparison of Hcy levels after stroke with Hcy levels of controls. The results by Howard et al. ${ }^{(36)}$ suggested that Hcy levels would be increased in blood collected later after the stroke. Therefore, the interpretation that a high Hcy level is a risk factor for stroke may be misleading; rather, it could be that the elevated Hcy is a consequence rather than a cause of the stroke.

Mezzano et al. ${ }^{(37)}$ investigated the relative contributions of inflammation and high Hcy to abnormal oxidative stress, endothelial activation/dysfunction and haemostatic activation in patients with chronic renal failure, and concluded that inflammation, endothelial cell dysfunction and haemostatic activation emerge as a major cardiovascular risk in chronic renal failure.

Observational studies support the importance of modifying lifestyle-related risk factors such as diet, physical activity and alcohol use in stroke prevention. Moderately elevated Hcy levels may be associated with stroke and are associated with deficiency of dietary intake of folate, vitamin $\mathrm{B}_{6}$ and vitamin $\mathrm{B}_{12}$. Consumption of a diet rich in fruits, vegetables, folate, $\mathrm{K}, \mathrm{Ca}, \mathrm{Mg}$, dietary fibre, fish and 


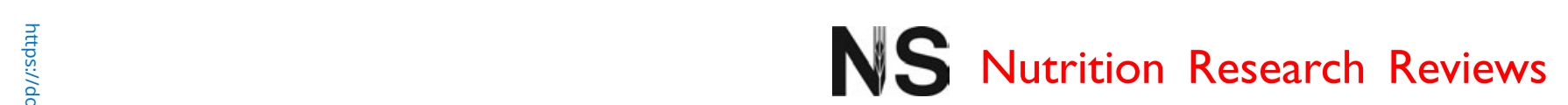

Table 1. B vitamins, homocysteine (Hcy) and stroke

\section{Study}

Levels of Hcy and risk of ischaemic stroke

Hcy and risk of stroke in middle-aged British men

Perry et al. (1995) ${ }^{(92)}$

Giles et al. (1998) (91)

Robinson et al. (1998) $)^{(60)}$

Hcy, B vitamins and vascular diseases

Beamer et al. (1999) ${ }^{(67)}$

Bots et al. (1999) ${ }^{(95)}$

Clarke \& Armitage $(2000)^{(74)}$

Fallon et al. (2001) $)^{(94)}$

Yoo \& Lee $(2001)^{(165)}$

Bazzano et al. (2002) ${ }^{(63)}$

Howard et al. (2002) $)^{(36)}$
Study focus

Subjects

Vitamin use in patients with ischaemic stroke

Hcy, myocardial infarction and stroke in the elderly: the Rotterdam Study

Vitamin supplements and CVD risk

Risk of ischaemic stroke and Hcy: the Caerphilly study

Elevated Hcy in elderly patients with stroke

Dietary intake of folate and risk of stroke and CVD

Hcy in the acute phase after stroke

\section{6 male physicians aged 40-84 years}

107 stroke patients, 118 controls

4534 US adults aged $\geq 35$ years

750 patients with vascular disease, 800 control subjects

231 stroke patients

104 myocardial infarct patients,

120 stroke patients, 533 control subjects

A meta-analysis of twelve randomised trials

2254 men aged $50-64$ years

Fifty stroke patients, thirty-five controls

9764 men and women aged 25-74 years

Seventy-six stroke patients aged 40-85 years

43732 men free of CVD and diabetes at baseline aged $40-75$ years
Results

The data were compatible with a small but NS association between elevated plasma Hcy and risk of ischaemic stroke

Hcy was significantly higher among stroke patients than controls

Hcy concentration was independently associated with an increased likelihood of non-fatal stroke. This association was present in both black and white adults

High Hcy is associated with an elevated risk of vascular disease independent of all traditional risk factors. Low folate and vitamin $B_{6}$ confer an increased risk of atherosclerosis

Use of vitamin supplements may be associated with lower levels of Hcy in elderly individuals whether or not stroke or stroke-related risk factors are present increased with total Hcy

Dietary folate reduced Hcy levels by $25 \%$. Vitamin $\mathrm{B}_{12}$ produced an additional reduction in blood Hcy of $7 \%$, whereas vitamin $\mathrm{B}_{6}$ did not have any significant effect

No significant relationship between Hcy and ischaemic stroke was observed in this cohort. However, its aetiological importance may be greater for premature ischaemic strokes ( $<65$ years)

Those elderly with elevated asymmetric dimethylarginine concentrations are at increased risk for ischaemic stroke; this may account for increased risk of stroke in patients with hyperhomocysteinaemia

Increasing dietary intake of folate from food sources may be an important approach to the prevention of CVD in the US population

Hcy levels at baseline of 11.3 (SEM 0.5) $\mu \mathrm{mol} / \mathrm{l}$ increased consistently to 12.0 (SEM 0.05 ), 12.4 (SEM 0.5), 13.3 (SEM 0.5) and 13.7 (SEM 0.7 ) $\mu \mathrm{mol} / \mathrm{l}$ at days $3,5,7$ and $10-14$, respectively, after stroke. These data sugges that the clinical interpretation of Hcy afte stroke and the eligibility for clinical trials assessing treatment for elevated Hcy levels require an adjustment in time since stroke and risk of stroke
Intake of vitamin $B_{12}$, but not $B_{6}$, was inversely

associated with risk of ischaemic stroke.

Increased folate intake was associated

with decreased risk of ischaemic stroke in men 
Iso $(2005)^{(166)}$

Intervention studies

Spence et al. $(2001)^{(69)}$

VITATOPS Trial Study Group (2002) ${ }^{(68)}$

Lonn et al. (2006) ${ }^{(65)}$

Albert et al. $(2008)^{(64)}$

Editorials and reviews

Kuller \& Evans (1998) ${ }^{(90)}$

Perry $(1999)^{(77,78)}$

Goldstein (2000) ${ }^{(76)}$

Robinson (2000) ${ }^{(15)}$

Rosenberg (2001)

Hankey (2002) ${ }^{(79)}$
Elevated Hcy and risk of total stroke and its subtypes

1846 Japanese subjects

3688 stroke patients,

aged $\geq 35$ years

Vitamins to prevent stroke

Hcy and folic acid and B vitamins in vascular disease

Daily intake of folic acid and $B$ vitamins and risk of

cardiovascular events and total mortality

Hcy, vitamins and CVD

Editorial

Hcy and risk of stroke

Review

Review

Editorial

Review

Editorial
High serum Hcy level $(>11.0 \mu \mathrm{mol} / \mathrm{l})$ was associated with a three-fold higher risk of total stroke. The excess risk was confined to ischaemic stroke, more specifically lacunar infarction

The VISP study is a double-masked, randomised, multicentre clinical trial designed to determine if, in addition to best medical/surgical management, high-dose folic acid, vitamin $\mathrm{B}_{6}$ and vitamin $B_{12}$ supplements will reduce recurrent stroke compared with lower doses of these vitamins

The VITATOPS study follow-up of 8000 patients between 2000 and 2009 provided a reliable estimate of the safety and effectiveness of dietary supplementation with folic acid vitamin $B_{12}$ and vitamin $B_{6}$ in reducing recurrent serious vascular events and transient ischaemic attacks stroke

Supplements combining folic acid $(2.5 \mathrm{mg})$ and vitamins $B_{6}(50 \mathrm{mg})$ and $B_{12}(1 \mathrm{mg})$ did not reduce the risk of major cardiovascular events in patients with vascular disease After 7.3 years of treatment and follow-up, a combination pill of folic acid $(2.5 \mathrm{mg})$, vitamin $\mathrm{B}_{6}$ $(50 \mathrm{mg})$ and vitamin $B_{12}(1 \mathrm{mg})$ did not reduce a combined end point of total cardiovascular events among high-risk women, despite significant Hcy lowering

Possible associations between Hcy, B vitamins and vascular disease

High Hcy in apparently well-nourished populations and the tendency of high Hcy with ageing, and the effects of Hcy on stroke. Reduction of Hcy will have profound implications for public health

Association between moderately elevated levels of Hcy and stroke. Patients with chronic inflammation, as well as those with chronic or acute infection, are at elevated stroke risk

Routine measurement of Hcy still remains speculative until the results of some of the intervention trials became known

Importance of $\mathrm{B}$ vitamins $\left(\mathrm{B}_{6}\right.$ and $\left.\mathrm{B}_{12}\right)$ and folate in neurocognitive and other neurological functions

Plasma Hcy and routine treatment of high Hcy with vitamins to prevent symptomatic cerebrovascular disease remains insufficient 


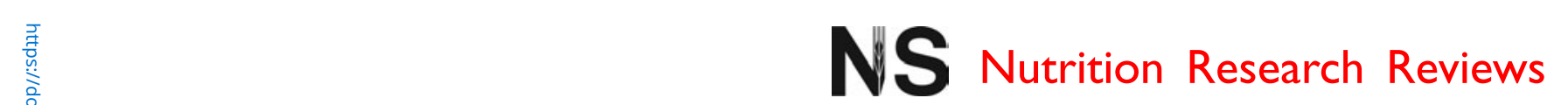

Table 2. Antioxidant vitamins $E$ and $C$ and stroke

\begin{tabular}{|c|c|}
\hline Study & Study focus \\
\hline \multicolumn{2}{|l|}{ Observational studies } \\
\hline Arria et al. (1990) $)^{(122)}$ & Vitamin E deficiency \\
\hline Gale et al. $(1995)^{(6)}$ & $\begin{array}{l}\text { Vitamin } C \text { and risk of death from } \\
\text { stroke }\end{array}$ \\
\hline Gillman et al. (1995) & $\begin{array}{l}\text { Intake of fruits and vegetables } \\
\text { and stroke }\end{array}$ \\
\hline Keli et al. $(1996)^{(167)}$ & $\begin{array}{l}\text { Antioxidants and stroke: the } \\
\text { Zutphen study }\end{array}$ \\
\hline Daviglus et al. $(1997)^{(168)}$ & $\begin{array}{l}\text { Vitamin C and stroke. The } \\
\text { CWE Study }\end{array}$ \\
\hline
\end{tabular}

Subjects

Results

Schmidt et al. $(1998)^{(127)}$

Simon et al. $(1998)^{(140)}$

Ascherio et al. (1999) ${ }^{(17)}$

Foy et al. (1999) ${ }^{(138)}$

Joshipura et al. (1999) ${ }^{(147)}$

Perkins et al. (1999) ${ }^{(126)}$

Simon \& Hudes $(1999)^{(21)}$

Cherubini et al. (2000) $)^{(158)}$

Yochum et al. (2000) (24)
Antioxidants and cognitive function

Vitamin C, CVD and stroke. Second NHNE Survey

Vitamins $E$ and $C$ and risk of stroke

Antioxidants and $A D$, vascular disease and PD

\section{Fruit and vegetable intake} and stroke

Vitamins $\mathrm{E}, \mathrm{C}$ and $\mathrm{A}$, carotenoids Se and poor memory performance

Vitamin C and CVD. Third NHNE Survey

Vitamins $\mathrm{C}$ and $\mathrm{E}, \mathrm{SOD}$ and glutathione peroxidase in stroke patients

Antioxidants and risk of death from stroke
Forty-two female patients with chronic cholestatic liver disease

730 men and women who had no history or symptoms of stroke, aged $\geq 65$ years

832 men aged $45-65$ years

552 men aged 50-69 years

1843 middle-aged men

1769 subjects with no history or signs of neuropsychiatric disease, aged $50-75$ years 6624 US men and women

43738 men who did not have CVD or diabetes, aged $40-75$ years

Seventy-nine patients with $A D$, thirty-seven patients with vascular disease, eighteen patients with PD

114279 men and women aged $34-75$ years

4809 non-Hispanic white, non-Hispanic black and Mexican-American elderly

7658 men and women

Thirty-eight control subjects, thirty-eight subjects with acute ischaemic stroke

34492 postmenopausal women
Vitamin E deficiency may underlie psychomotor and neurological disturbance in adult patients with chronic cholestatic liver disease

Low vitamin C status was associated with

highest mortality from stroke. The relationship between vitamin $C$ intake and stroke was independent of social class and other dietary variables

Fruits and vegetables protect against development of stroke in men

Intake of vitamins $C$ and $E$ was not associated with stroke risk

A modest decrease in risk of stroke with higher intake of $\beta$-carotene and vitamin $C$ intake was observed. These data do not provide definitive evidence that a high intake of antioxidant vitamins decreases the risk of stroke

Dietary antioxidants appear to protect against cognitive impairment in older individuals

Serum ascorbic acid levels were independently associated with prevalence of $\mathrm{CHD}$ and stroke; a $5 \mathrm{mg} / \mathrm{l}$ increase in serum ascorbic acid level was associated with an $11 \%$ reduction in $\mathrm{CHD}$ and stroke prevalence

Vitamin $E$ and $C$ supplements and specific carotenoids did not seem to substantially reduce the risk of stroke in this cohort

$A$ reduction in plasma antioxidants in patients with dementia. Increased free radical activity in vascular disease and PD may be associated with concomitant AD pathology

Consumption of fruit and vegetables, particularly cruciferous and green leafy vegetables and citrus fruit and juice, provide a protective effect against risk of ischaemic stroke

Decreasing serum levels of vitamin E were associated with poor memory after adjustment for age, education, income, vascular risk factors, and other trace elements and minerals

A higher intake of vitamin $C$ may be associated with a decreased risk of angina among drinkers

Reduction of antioxidants immediately after ischaemic stroke, possibly as a consequence of increased oxidative stress. A specific antioxidant profile is associated with a poor early outcome

An inverse association between death from stroke and intakes of vitamin $E$ from food was observed 
Hirvonen et al. $(2000)^{(169)}$

Vitamins $\mathrm{C}$ and $\mathrm{E}$ and risk of stroke

Yokoyama et al. $(2000)^{(170)}$

Polidori et al. (2001)

Kurl et al. (2002) ${ }^{(145)}$

Vokó et al. (2003) $)^{(172)}$

Myint et al. (2008) ${ }^{(146)}$

Intervention studies

Shorer et al. $(1996)^{(123)}$

Sano et al. (1997) ${ }^{(142)}$ Benson et al. (1999) ${ }^{(173)}$

Leppälä et al. $(2000)^{(18,129)}$

Lonn $(2005)^{(135)}$

Cook et al. $(2007)^{(148)}$

Reviews

Padh (1991) ${ }^{(143)}$

Ness et al. (1996) $)^{(141)}$

Launer \& Kalmijn

$(1998)^{(125)}$
Vitamin $\mathrm{C}$ and stroke. The Shibata Study

Vitamins $C$ and $E$, uric acid and ubiquinol-10

Vitamin C and risk of stroke

Intake of antioxidants from food and risk of stroke

Plasma vitamin $\mathrm{C}$ concentrations and risk of incident stroke

Vitamin E deficiency

Vitamin $E$ and $A D$

Vitamin $E$ and stroke.

The NOMAS Study

Vitamin E supplementation

and stroke

Vitamin E and cardiovascular events

Vitamins $C$ and $E$ and $\beta$-carotene cardiovascular events

Vitamin C: its biochemical functions

Vitamin C and CVD

Antioxidants and cognitive function and secondary prevention of
26593 male smokers,

aged $50-69$ years

2121 Japanese men and women aged $\geq 40$ years

Forty control subjects, thirteen patients with intracranial haemorrhage, fifteen patients with head trauma

2419 men with no history of stroke at baseline examination aged 42-60 years

5197 participants

20649 men and women without prevalent stroke at baseline aged $40-79$ years

Four siblings

341 AD patients

342 stroke patients, 501 control subjects

29133 male smokers aged 50-69 years

3994 patients with vascular disease or diabetes mellitus, aged $\geq 55$ years

8171 female health professionals at increased risk of CVD aged $\geq 40$ years

Review

Review

Review
Vitamin E was not associated with any subtype of stroke. Dietary vitamin C was inversely associated with risk for intracerebral haemorrhage, whereas no association was found between intake of vitamin $\mathrm{C}$ and risks for cerebral infarction and subarachnoid haemorrhage

Serum vitamin $\mathrm{C}$ concentration was inversely associated with incidence of stroke, both cerebral infarction and haemorrhagic stroke

Intracranial and head trauma patients had significantly lower plasma levels of vitamin C compared with healthy subjects. Ascorbic acid was significantly inversely correlated with the severity of the neurological impairment and with the major diameter of the lesion

Low plasma vitamin $\mathrm{C}$ was associated with an increased risk of stroke, especially among hypertensive and overweight men

High dietary intake of antioxidants, in particular vitamin C and - in smokers - vitamin E, reduced the risk of stroke

Plasma vitamin C concentrations may serve as a biological marker of lifestyle or other factors associated with reduced stroke risk and may be usefu in identifying those at high risk of stroke

Vitamin E administration in pharmacological doses improved the neurological condition in two patients and also corrected some of the patients' erythrocyte cell abnormalities

Vitamin $E$ slowed the progression of $A D$

Vitamin E supplementation showed a protective effect against ischaemic stroke

Vitamin E supplementation appears to have a significant effect in preventing ischaemic stroke in high-risk hypertensive patients

In patients with vascular disease or diabetes mellitus, long-term vitamin E supplementation does not prevent cancer or major cardiovascular events and may increase the risk for heart failure

There were no overall effects of ascorbic acid, vitamin $E$ or $\beta$-carotene on cardiovascular events among women at high risk for CVD

Ascorbate and other antioxidant nutrients are presumed to play a pivotal role in minimising the damage from oxidative products

Vitamin C's protective effect against stroke is well documented whereas the evidence that vitamin $\mathrm{C}$ is protective against $\mathrm{CHD}$ is less consistent

Effect of antioxidants on cognitive impairment or dementia needs further investigation 
milk may protect against stroke ${ }^{(22,38-42)}$. There is also evidence that a low serum albumin may be causally linked to stroke risk and outcome and that a significant number of stroke patients are undernourished on admission and their nutritional status deteriorates further whilst in hospi$\mathrm{tal}^{(40,43,44)}$ (about a fifth of patients with acute stroke are malnourished on admission to hospital). Moreover, patients' nutritional status often deteriorates thereafter because of increased metabolic demands, which cannot be met due to feeding difficulties. Poor nutritional intake may result from a reduced consciousness level, unsafe swallowing, arm or facial weakness, poor mobility, or ill-fitting dentures ${ }^{(45-48)}$. Large randomised trials are now in progress to identify the optimum feeding policies for stroke patients. Experimental research has consistently suggested that diet-related factors play an important role in cognitive functions in ageing. In humans, a number of epidemiological case-control and prospective studies analysed the association between nutrition, particularly fatty acids and antioxidant molecules (vitamins A, E and C, $\beta$-carotene and polyphenols) and cognition and risk of stroke ${ }^{(49)}$. In fact, intensive research has indicated that subclinical deficiencies of essential nutrients such as antioxidants (vitamins $\mathrm{C}$ and $\mathrm{E}$ ), $\beta$-carotene, vitamin $B_{12}$, vitamin $B_{6}$ and folate in combination with nutrition-related disorders, such as hypercholesterolaemia, hypertriacylglycerolaemia, hypertension and diabetes, are important risk factors associated with cognitive impairment ${ }^{(8)}$. Current scientific evidence also suggests a protective role for fruits and vegetables in the prevention of $\mathrm{CHD}$, and evidence is accumulating towards a protective role in stroke $\mathrm{e}^{(22,42,50-52)}$. On the other hand, intake of monounsaturated fat has been associated with reduced risk of ischaemic stroke in men ${ }^{(53)}$. Another study has found that higher intake of wholegrain foods was associated with lower risk of ischaemic stroke among women, independent of known CVD risk factors. These prospective data support the notion that higher intake of whole grains may reduce the risk of ischaemic stroke ${ }^{(19)}$. Higher consumption of fish and $n$-3 PUFA is associated with a reduced risk of thrombotic infarction, primarily among women who do not take aspirin regularly ${ }^{(54)}$. Other authors also have reported that fish consumption is associated with a reduced risk from all-cause, IHD and stroke mortality at the population level ${ }^{(55)}$.

Thus, B vitamins and antioxidant nutrients have important roles in cell function and have been implicated in processes associated with ageing including vascular, inflammatory and neurological damage. A large body of evidence indicates that micronutrient status is an important determinant of vascular dysfunction and that deficiencies contribute to vasculature changes in the brain, risk of stroke, and alterations in brain function and cognitive impairment in the elderly. However, how these factors are causally interrelated remains poorly understood. Previous studies have focused on atherosclerosis and loss of innervation as the main changes involved in ageing-related vascular impairments.

\section{$B$ vitamins: folate, vitamin $B_{12}$ and vitamin $B_{6}$}

The major manifestation of folate deficiency is megaloblastic anaemia. Gastrointestinal disturbances may also 
accompany folate deficiency. Numerous animal studies have also shown that folate deficiency during pregnancy can impair proper development of fetal central nervous system structures. Folate deficiency in pregnant women is associated with an increased incidence of spina bifida and other neural defects ${ }^{(56)}$. Vitamin $B_{12}$ deficiency in adults is usually not the result of reduced dietary intake but rather reflects reduced intestinal absorption of the vitamin. A number of disease conditions can alter production of the intrinsic factor that is essential for absorption of vitamin $B_{12}$ from the intestine. Atrophic gastritis is an important cause of vitamin $\mathrm{B}_{12}$ malabsorption. This condition primarily affects the ability to extract vitamin $\mathrm{B}_{12}$ from foods. Deficiency of vitamin $\mathrm{B}_{12}$ impairs the ability of the bone marrow to produce erythrocytes and thus leads to anaemia, similar to what is observed with folate deficiency. Vitamin $B_{12}$ deficiency can also result in irreversible damage to the nervous system causing swelling, demyelination and death of neurons.

Evidence of the importance of the $\mathrm{B}$ vitamins folic acid, vitamin $\mathrm{B}_{12}$ and vitamin $\mathrm{B}_{6}$ for the wellbeing and normal function of the brain derives from data showing neurological and psychological dysfunction in vitamin-deficiency states and in cases of congenital defects of one-carbon metabolism. A review by Selhub et al. ${ }^{(57)}$ indicated that the status of these vitamins is frequently inadequate in the elderly and recent studies have shown associations between loss of cognitive function or Alzheimer's disease and inadequate B vitamin status. The authors suggest that low B vitamin intake may affect methylation reactions, which are crucial for normal brain function. Poor B vitamin status can also result in high Hcy, a risk factor for occlusive vascular disease, stroke and thrombosis and thus may contribute to brain ischaemia. Evidence of the importance of B vitamins $\left(\mathrm{B}_{12}, \mathrm{~B}_{6}\right.$ and folate) in neurocognitive and other neurological functions is derived from reported cases of severe vitamin deficiencies, particularly pernicious anaemia, or homozygous defects in genes that encode for enzymes of one-carbon metabolism ${ }^{(58)}$; however, the data from a recent systematic review of randomised trials do not yet provide adequate evidence of an effect of vitamin $B_{6}$ or $\mathrm{B}_{12}$ or folic acid supplementation, alone or in combination, on cognitive function testing in individuals with either normal or impaired cognitive function ${ }^{(59)}$. Low levels of folate and vitamin $\mathrm{B}_{6}$ have been regarded to confer an increased risk of atherosclerosis ${ }^{(60)}$. High plasma Hcy concentration is a risk factor for atherosclerosis, and circulating concentrations of Hcy are related to vitamin $\mathrm{B}_{12}$ status, as well as folate and vitamin $\mathrm{B}_{6}$. If elevated $\mathrm{Hcy}$ promotes cognitive dysfunction, then lowering Hcy by means of B vitamin supplementation may protect cognitive function by arresting or slowing the disease process ${ }^{(61)}$. Although elevated plasma Hcy concentrations have been implicated in the risk of cognitive impairment and dementia, it is unclear whether low vitamin $\mathrm{B}_{12}$ or folate status is responsible for cognitive decline ${ }^{(62)}$.

Various studies have suggested that a generous intake of folate and B vitamins may be beneficial in stroke prevention by reducing the level of plasma $\mathrm{Hcy}^{(60)}$. The association between dietary intake of folate and the subsequent risk of stroke and CVD is well documented. Participants in the
National Health and Nutrition Examination Survey I (NHANES I) included 9764 US men and women aged 25-74 years who were free of CVD at baseline. The results showed that the relative risk of incidence of stroke events was lower among subjects with dietary folate intake in the highest quartile $(405.0 \mu \mathrm{g} / \mathrm{d})$ compared with those in the lowest quartile $(99.0 \mu \mathrm{g} / \mathrm{d})$, after adjustment for established cardiovascular risk factors and dietary factors ${ }^{(63)}$. A recent study evaluated whether a combination of folic acid, vitamin $\mathrm{B}_{6}$ and vitamin $\mathrm{B}_{12}$ lowers the risk of CVD among high-risk women with and without CVD. A total of 5442 women who were US health professionals aged 42 years or older, with either a history of CVD or three or more coronary risk factors, were enrolled in a randomised, double-blind, placebo-controlled trial to receive a combination pill containing $2.5 \mathrm{mg}$ folic acid, $50 \mathrm{mg}$ vitamin $\mathrm{B}_{6}$ and $1 \mathrm{mg}$ vitamin $\mathrm{B}_{12}$. They were treated for 7.3 years from April 1998 until July 2005. After 7.3 years of treatment and follow-up, the combination of B vitamins tested did not reduce a combined end point of total cardiovascular events among high-risk women, despite significant Hcy lowering $^{(64)}$. In addition, the results of the Heart Outcomes Prevention Evaluation (HOPE-2) study, showed that combined daily administration of $2.5 \mathrm{mg}$ folic acid, $50 \mathrm{mg}$ vitamin $\mathrm{B}_{6}$ and $1 \mathrm{mg}$ vitamin $\mathrm{B}_{12}$ for 5 years had no beneficial effects on major vascular events in a high-risk vascular disease population ${ }^{(65)}$, although fewer patients assigned to active treatment than to placebo had a stroke (relative risk 0.75; $95 \%$ CI 0.59, 0.97). As well, Bønaa et al. ${ }^{(66)}$ evaluated the efficacy of Hcy-lowering treatment with $\mathrm{B}$ vitamins for secondary prevention in patients who had had an acute myocardial infarction. The trial included 3749 men and women who had had an acute myocardial infarction within $7 \mathrm{~d}$ before randomisation. Patients were randomly assigned, in a $2 \times 2$ factorial design, to receive one of the following four daily treatments: $0.8 \mathrm{mg}$ folic acid, $0.4 \mathrm{mg}$ vitamin $\mathrm{B}_{12}$ and $40 \mathrm{mg}$ vitamin $\mathrm{B}_{6} ; 0.8 \mathrm{mg}$ folic acid and $0.4 \mathrm{mg}$ vitamin $\mathrm{B}_{12} ; 40 \mathrm{mg}$ vitamin $\mathrm{B}_{6}$; or placebo. The primary end point during a median follow-up of 40 months was a composite of recurrent myocardial infarction, stroke and sudden death attributed to coronary artery disease. The authors conclude that treatment with B vitamins did not lower the risk of recurrent CVD after acute myocardial infarction.

The folic acid fortification programme in the USA has decreased the prevalence of low levels of folate and hyperhomocysteinaemia to $1 \%$ or lower ${ }^{(35)}$. Folate is distributed widely in green leafy vegetables, citrus fruits and animal products. The biologically active form of folic acid is tetrahydrofolic acid, which plays a key role in the transfer of one-carbon units, such as methyl, methylene and formyl groups, to the essential substrates involved in the synthesis of DNA, RNA and proteins. More specifically, tetrahydrofolic acid is involved in the enzymic reactions necessary for the synthesis of purine, thymidine and amino acids. Manifestations of folate deficiency, thereafter, not surprisingly, would result in impairment of cell division, accumulation of possibly toxic metabolites such as Hcy, and impairment of methylation reactions involved in the regulation of gene expression. Mechanistically speaking, current theory proposes that folate is essential for the 
synthesis of S-adenosylmethionine, which is involved in numerous methylation reactions. This methylation process is central to the biochemical basis of proper neuropsychiatric functioning.

A large body of evidence suggests that intake of folate and $\mathrm{B}$ vitamins may be beneficial in stroke prevention by reducing levels of plasma Hcy; however, limited information is available regarding dietary intake of vitamins or use of vitamin supplements by stroke patients. Beamer et al. ${ }^{(67)}$ collected information regarding the use of vitamin supplements from 231 patients with acute ischaemic stroke. These authors also recorded vitamin intake from ninety-four subjects with similar clinical risk factors for stroke, including hypertension, diabetes, myocardial ischaemia, and fifty-nine healthy community volunteers who denied the presence of stroke risk factors and who were matched in age with the two vascular groups. Fewer subjects who had stroke were taking vitamins, compared with healthy elderly community volunteers. In addition, Hcy levels available from forty-nine stroke patients, thirty-one patients with stroke risk factors and seven control subjects were significantly lower in subjects taking vitamins. The pattern of lower Hcy values with vitamin use was consistent across groups, including stroke patients (13.9 (SD 6.7) (SD 4.1) $\mu \mathrm{mol} / \mathrm{l}$ ), at-risk elderly subjects (13.5 (SD 4.3) v. 15.0 (SD 6.9) $\mu \mathrm{mol} / \mathrm{l}$ ) and healthy elderly subjects (7.1 (SD 0.1) v. 10.5 (SD 2.3) $\mu \mathrm{mol} / \mathrm{l}$ ). It was concluded that Hcy levels are influenced by a complex interaction of sex, dietary levels of protein intake, dietary and/or supplemental vitamin use and cardiovascular risk factors. These results suggest that the use of vitamin supplements may be associated with lower levels of Hcy in elderly individuals whether or not stroke or stroke-related risk factors are present. Also, these data suggest that less frequent use of vitamin supplementation in the elderly may be associated with an increased risk for stroke ${ }^{(67)}$. Different epidemiological studies suggest that raised plasma concentrations of total Hcy may be a common, causal and treatable risk factor for atherothromboembolic ischaemic stroke. Therefore, a study aimed to assess the effect of Vitamins to Prevent Stroke (VITATOPS) - an international, multi-centre, randomised, double-blind, placebo-controlled clinical trial - using a multivitamin therapy (folic acid $2 \mathrm{mg}$, vitamin $\mathrm{B}_{6} 25 \mathrm{mg}$, vitamin $\mathrm{B}_{12}$ $500 \mu \mathrm{g}$ ) is currently going on. It is planned that 8000 patients will be randomised and followed up for a mean period of 2.5 years (range $1-8$ years) by the end of $2009^{(68)}$. This study is expected to generate relevant data on the potential role of these nutrients on stroke and other atherothromboembolic vascular events in patients with recent stroke or transient ischaemic attacks. Publication of the results of the landmark Vitamin Intervention for Stroke Prevention (VISP) Trial is the first evidence from a large randomised controlled trial of the effect of lowering total Hcy via folic acid-based multiple B vitamin supplementation on the incidence of 'hard' clinical events, such as recurrent stroke, in patients with recent ischaemic stroke $^{(69,70)}$. Hankey \& Eikelboom ${ }^{(71)}$ believe that the Hcy hypothesis of atherothrombotic vascular disease in general, and stroke in particular, remains viable. Two studies using different methods have yielded consistent results in support of the hypothesis ${ }^{(72,73)}$
Several studies are in progress to determine whether treatment with folic acid in combination with vitamins $\mathrm{B}_{6}$ and $B_{12}$ will reduce the risk of stroke in patients with increased serum Hcy. A meta-analysis of twelve randomised trials of vitamin supplements to lower Hcy levels was carried out to determine the optimal dose of folic acid required to lower Hcy levels and to assess whether vitamin $B_{12}$ or vitamin $B_{6}$ had additive effects ${ }^{(74)}$. This meta-analysis demonstrated that reductions in blood Hcy levels were greater at higher pre-treatment blood Hcy levels and at lower pre-treatment folate concentrations. After standardisation for a pre-treatment Hcy concentration of $12 \mu \mathrm{mol} / \mathrm{l}$ and folate concentration of $12 \mathrm{nmol} / \mathrm{l}$ (approximate average concentrations for Western populations), dietary folate acid reduced Hcy levels by 25 (95\% CI 23, 28) $\%$, with similar effects in a daily dosage ranging from 0.5 to $5 \mathrm{mg}$. Vitamin $\mathrm{B}_{12}$ (mean $0.5 \mathrm{mg}$ ) produced an additional reduction in blood Hcy of $7 \%$, whereas vitamin $\mathrm{B}_{6}$ (mean $16.5 \mathrm{mg}$ ) did not have any significant effect. Hence, in typical populations, daily supplementation with both 0.5 to $5 \mathrm{mg}$ folic acid and about $0.5 \mathrm{mg}$ vitamin $\mathrm{B}_{12}$ would be expected to reduce Hcy levels by one-quarter to one-third (from about $12 \mu \mathrm{mol} / \mathrm{l}$ to about 8 to $9 \mu \mathrm{mol} / \mathrm{l}$ ). Large-scale randomised trials of such regimens are now required to determine whether lowering Hcy levels by folic acid and vitamin $B_{12}$, with or without added vitamin $B_{6}$, reduces the risk of vascular disease.

In this sense, it has also to be considered on one hand that high doses of folic acid may mask the megaloblastic anaemia due to vitamin $\mathrm{B}_{12}$ deficiency seen in elderly individuals as a result of atrophic gastritis. On the other hand, we have to be aware that vitamin $\mathrm{B}_{6}$ status is primarily a determinant of postprandial Hcy levels, but not fasting levels. Thus, in studies of B vitamin supplements and Hcy, it often appears that vitamin $B_{6}$ has little effect on Hcy levels because these studies typically only look at fasting Hcy levels.

In addition, it is interesting to consider the issue of folic acid fortification. In the USA and Canada, folic acid fortification of enriched grain products was fully implemented by 1998 . Yang et al. ${ }^{(75)}$ evaluated trends in stroke-related mortality before and after folic acid fortification in the USA and Canada and, as a comparison, during the same period in England and Wales, where fortification is not required. They observed a trend consistent with the hypothesis that folic acid fortification is contributing to a reduction in stroke deaths.

Patients with chronic inflammation as well as those with chronic or acute infection are at elevated stroke risk ${ }^{(76)}$. Due to the high prevalence of high Hcy among apparently wellnourished populations and the tendency for Hcy concentrations to increase with age, and the effects of Hcy on stroke risk, lowering the levels of Hcy may have profound implications for public health ${ }^{(77,78)}$. However, according to Robinson $^{(15)}$, the benefit of routine measurement of Hcy concentrations remains speculative until the results of some of the intervention trials become known. In the same sense, Hankey ${ }^{(79)}$ concluded that there is not sufficient evidence to recommend routine screening of plasma Hcy and routine treatment of high Hcy concentrations with vitamins to prevent symptomatic cerebrovascular disease. 


\section{Homocysteine}

A high Hcy concentration is an independent risk factor for coronary artery disease, stroke, peripheral vascular atherosclerosis, and for arterial and venous thromboembolism, although the mechanisms for this effect remain poorly understood. The association between cognitive function and risk of death from stroke suggests that cerebrovascular disease is an important cause of declining cognitive function. Hcy is believed to cause atherogenesis and thrombogenesis via endothelial damage, focal vascular smooth muscle proliferation probably causing irregular vascular contraction and coagulation abnormalities ${ }^{(80)}$. The significance of any association between CVD and stroke, and circulating Hcy concentrations is attracting considerable attention ${ }^{(80-90)}$. Morris et al. ${ }^{(89)}$ evaluated the association between serum Hcy concentration and selfreport heart attack or stroke in adult male and female participants in the Third National Health and Nutrition Examination Survey (NHANES III). The study reported 2.4 times more episodes of heart attack or stroke in men with Hcy concentration of $>12 \mu \mathrm{mol} / \mathrm{l}$ than among individuals with lower values. According to Kuller \& Evans ${ }^{(90)}$, Hcy and B vitamin levels may contribute to the development of vascular disease through mechanisms independent of the atherosclerosis process. In fact, whereas high Hcy levels are directly related to the development of atherosclerosis, a decrease in folate or vitamin $\mathrm{B}_{12}$ and vitamin $\mathrm{B}_{6}$ increases the risk of vascular disease independently of atherosclerosis. High Hcy levels could be associated with an enhancement of inflammatory process and increased risk of thrombosis. Giles et al. ${ }^{(91)}$ found that in a representative sample of US adults, Hcy concentration was independently associated with an increased likelihood of non-fatal stroke, and this association was present in both black and white adults. In a different study, Perry et al. ${ }^{(92)}$ measured serum Hcy levels in 107 cases and 118 control males, matched for age and without a history of stroke at the time of screening; some of them did develop stroke or myocardial infarction during follow-up. Levels of Hcy were not very high but lower in controls $(11.3-12.6 \mu \mathrm{mol} / \mathrm{l})$ than among cases (12.7$14.8 \mu \mathrm{mol} / \mathrm{l})$. Other studies have also indicated that small differences in Hcy levels may significantly contribute to increase the risk of ischaemic stroke ${ }^{(93-95)}$.

A high concentration of Hcy appears to have significant effect on platelets' function and it may be relevant to bloodbrain barrier changes. The neurotoxicity of Hcy acting through the overstimulation of $N$-methyl-D-aspartate receptors could be one of the mechanisms that contribute to neuronal damage in high $\mathrm{Hcy}^{(96)}$. In addition to a possible direct pathological effect of Hcy on the endothelium, elevated Hcy levels lead to the development and progression of vascular disease by affecting platelets' function and aggregation ${ }^{(97)}$. Mutus et al. ${ }^{(98)}$ showed that Hcy-induced inhibition of NO production in platelets was lower in platelets from diabetic patients than in platelets from control subjects. Other studies have suggested that moderate to high Hcy levels play a role in the development of a thrombogenic state through oxidative stress-mediated insult ${ }^{(99)}$.

High Hcy levels are also associated with atherosclerosis, thromboembolism and vascular endothelial cell injury ${ }^{(100,101)}$. The effect of Hcy in developing thrombosis may be associated with an inhibitory action on endothelial cell thrombomodulin expression, which was independent of platelet aggregation or heparin cofactor activity ${ }^{(102)}$. In severe high homocysteinaemia, circulating endothelial cells have been detected ${ }^{(103,104)}$, indicative of endothelial cell death. Also, Hcy induces apoptosis in human umbilical vein endothelial cells by activation of the unfolded protein response ${ }^{(105)}$. In the same way, Hcy-thiolactone induced endothelial cell apoptosis in a concentration-dependent manner with concentrations that ranged from 50 to $200 \mu \mathrm{mol} / \mathrm{l}$, independently of the caspase pathway ${ }^{(106)}$. Wang et $a l^{(107)}$, using a concentration that overlaps clinically, observed levels of $10-50 \mu \mathrm{mol}$ Hcy per litre, inhibited DNA synthesis in vascular endothelial cells and arrested their growth at the G1 phase of the cell cycle. Chambers et al. ${ }^{(108)}$ detected endothelial dysfunction at Hcy concentrations similar to those associated with increased risk of myocardial infarction and stroke. Interestingly, pre-treatment of cells with vitamin $\mathrm{C}$ prevented the decrease in flow-mediated dilatation after methionine. Thus, elevation of Hcy concentration appears to be associated with an acute impairment of vascular endothelial cell function that can be prevented by pretreatment with vitamin $C$ in healthy subjects ${ }^{(108)}$. Another important finding is the molecular association between the atherosclerotic process and high Hcy. Li et al. ${ }^{(109)}$, using a cDNA microarray, found an unexpected link between Hcy and cholesterol dysregulation with increased levels of 3-hydroxy-3-methylglutaryl coenzyme A reductase mRNA and protein in endothelial cells, suggesting a possible role of Hcy-induced changes in endothelial cells. Interestingly, the use of statins improved endothelial NO production in Hcy-treated endothelial cells. To study the mechanisms by which Hcy may promote vascular modifications, Kokame et $a l .{ }^{(110)}$ applied a non-radioactive differential display analysis to evaluate changes in gene expression induced by Hcy in human umbilical vein endothelial cell culture. They identified six up-regulated genes and one down-regulated gene, revealing that Hcy alters the expression of multiple proteins, some of them associated with the endoplasmic reticulum stress response ${ }^{(111)}$. Outinen et al. ${ }^{(112)}$ demonstrated using human umbilical endothelial cells that Hcy causes adverse effects on the endoplasmic reticulum, altering the expression of several genes sensitive to endoplasmic reticulum stress. They also showed that Hcy altered various genes known to mediate cell growth and differentiation. In addition, they observed that Hcy altered the gene profile involved in the expression of cellular proteins such as glutathione peroxidase and superoxide dismutase, thus potentially enhancing the cytotoxic effects of agents or conditions known to cause oxidative damage ${ }^{(112)}$. Another study using human endothelial cells demonstrated that Hcy may act upon the vasculature through activation of kinases such as Jun N-terminal kinase/stressactivated protein kinase (JNK/SAPK), and subsequent expression of transcription factor ATF3 involved in the regulation of synthesis of proteins critical for endothelial cell function ${ }^{(113)}$.

Pathophysiological levels of L-Hcy can alter endothelial cell function. Poddar et al. ${ }^{(114)}$ demonstrated that cultured 
human aortic endothelial cells exposed to as little as $10 \mu \mathrm{M}-$ DL-Hcy up-regulated the expression of chemokines such as monocyte chemoattractant protein-1 (MCP-1) and IL-8. Maximal expression was achieved with $50 \mu \mathrm{M}-\mathrm{DL}-\mathrm{Hcy}$ within $2-4 \mathrm{~h}$ of incubation. This suggests that Hcy may contribute to the initiation and progression of vascular disease by promoting leucocyte recruitment. Holven et $a l .{ }^{(115)}$ suggested that Hcy exerts its atherogenic effects in part by enhancing chemokine expression in cells involved in atherogenesis and that folic acid supplementation may down-regulate these inflammatory responses. On the other hand, the recruitment of monocytes is an important event in atherogenesis. MCP-1 is a potent chemokine that stimulates monocyte migration into the intima of arterial walls. In the same manner, Wang et al. ${ }^{(116)}$ investigated the effect of Hcy on MCP-1 expression in macrophages and the underlying mechanism of this effect. They demonstrated that Hcy, at pathological concentration, stimulates MCP-1 expression in human monocytic cell macrophages via NF- $\mathrm{KB}$ activation. Also, in this sense, another study demonstrated that Hcy might increase monocyte recruitment into developing atherosclerotic lesions by up-regulating MCP-1 and IL-8 expression in vascular smooth muscle cells ${ }^{(117)}$. In addition, a study demonstrated that Hcy inhibits TNF- $\alpha$-induced activation of the endothelium via the modulation of NF- $\mathrm{BB}$ activity. These results indicate that Hcy alters the response to injury of endothelial cells, which may have fundamental impacts on mechanisms of leucocyte recruitment to sites of inflammation. These findings may indicate a novel pathway by which Hcy is involved in vascular disorders associated with homocystinuria ${ }^{(118)}$.

\section{Antioxidant vitamins $\mathbf{E}$ and $\mathbf{C}$}

Vitamins $\mathrm{E}$ and $\mathrm{C}$ have been investigated in a large number of epidemiological, clinical and experimental studies $^{(119-121)}$. Antioxidant nutrients have important roles in cell function and have been implicated in processes associated with ageing, including vascular, inflammatory and neurological damage. The evidence regarding the link between vitamin E deficiency and neurological sequelae in man is now firmly established. That several neuropathological observations are associated with vitamin E deficiency indicates the importance of this nutrient in the central nervous system for normal neurological function ${ }^{(122-124)}$. Vitamin E's protective effect against cognitive decline and neurodegenerative disease has been explored in several epidemiological and clinical studies during the last decade $^{(125,126)}$. When plasma antioxidants and cognitive performance in middle-aged and older adults were measured in the Austrian Stroke Prevention Study, vitamin E was found to be significantly associated with cognitive functioning ${ }^{(127)}$. Rosenblum et al. ${ }^{(128)}$ reported a protective effect by vitamin $\mathrm{E}$ to ameliorate the adverse effects of endothelial cell injury from brain ischaemia.

Recent studies have shown that increased vitamin E intake slows the progression of dementia and may improve central nervous system function. A study evaluated the intake of antioxidants and the risk of stroke, providing evidence that vitamin $\mathrm{E}$ might be of value in reducing the risk of stroke. This study looked at the diets of over 34000 postmenopausal women as well as their risk of death from stroke $^{(24)}$. A total of 215 of the women died of strokes during the study period. Interestingly, the paper noted that the greater the amount of vitamin $\mathrm{E}$ in the diet, the lower the risk of death from stroke ${ }^{(24)}$. There was a suggestion of an inverse association between specific foods rich in vitamin $\mathrm{E}$ and death from stroke. However, these authors found no reduction in risk of death from stroke with vitamin $\mathrm{E}$ supplements, which might indicate that vitamin $\mathrm{E}$ intake was in fact a surrogate marker for some other protective agents in the diet.

Prospective studies that examined the association between vitamin $\mathrm{E}$ intake and death from stroke have produced conflicting results. This is an important area of research that still remains poorly studied because in most of the studies there is no detailed information of the dose, frequency and time that these subjects were taking vitamin E supplements. However, the Health Professionals FollowUp Study looked at nearly 44000 men aged $40-75$ years without known heart disease or diabetes, and measured the incidence of stroke, including deaths and all occurrences of strokes, and compared it with the participants' intake of various antioxidants ${ }^{(17)}$. They also found no reduction in the incidence of stroke in those who took antioxidant supplements. A study conducted in Helsinki, Finland, looked at nearly 30000 male smokers for 6 years ${ }^{(18)}$. Participants were assigned to take supplements of vitamin E, $\beta$-carotene or placebo. More than 1000 suffered strokes during the study period. Of those, fewer than 200 had the type of stroke caused by leaking blood vessels in the brain, and about 800 had the sort of stroke caused by blockage of blood vessels from atherosclerosis. The researchers found that taking vitamin $\mathrm{E}$ supplements increased the risk of strokes from bleeding in the brain among smokers, but decreased the risk of strokes caused by atherosclerosis in those participants who had high blood pressure. Strokes from atherosclerosis also decreased among the diabetics who took vitamin $\mathrm{E}$ supplements, with no associated increased risk in bleeding strokes ${ }^{(18,129)}$. Thus, the researchers concluded that vitamin E supplementation may prevent ischaemic stroke in high-risk hypertensive patients, but further studies are needed. Results from a study on vitamin supplements, reported at the 51st annual meeting of the American Academy of Neurology in Toronto ${ }^{(130)}$, showed that supplements containing even modest amounts of vitamin $\mathrm{E}$ are protective against ischaemic stroke. This study shows that vitamin E supplements can reduce stroke risk by $53 \%$. The total vitamin $\mathrm{E}$ intake of $27 \mathrm{IU} / \mathrm{d}$ $(18 \mathrm{mg} / \mathrm{d})$ was significantly lower in subjects who had sustained an ischaemic stroke than in individuals who had not had a stroke - their mean total daily intake was $58 \mathrm{IU} / \mathrm{d}$ $(38.7 \mathrm{mg} / \mathrm{d})$. Also, controls who had not had a stroke were also twice as likely to take a vitamin supplement compared with stroke patients.

Megadoses of vitamin E appear to significantly reduce the levels of inflammation. Devaraj \& Jialal ${ }^{(131)}$ studied fortyseven men and women with adult-onset, or type 2, diabetes and twenty-five healthy volunteers. They received $1200 \mathrm{IU}$ $(800 \mathrm{mg})$ vitamin $\mathrm{E}$ daily for 3 months. Before treatment, individuals with diabetes produced about two-fold as much $\mathrm{C}$-reactive protein compared with the healthy individuals, 
and individuals with mild diabetes showed about $33 \%$ higher C-reactive protein levels compared with healthy volunteers. Interestingly, vitamin $\mathrm{E}$ supplementation lowered C-reactive protein levels. In addition, these authors also reported that, after taking vitamin $\mathrm{E}$, cells from the volunteers produced about $70 \%$ less IL-6 as was generated by cells from blood drawn before taking vitamin $\mathrm{E}$.

Hodis et al. ${ }^{(132)}$ report results from the Vitamin E Atherosclerosis Progression Study (VEAPS), a randomised clinical trial designed to determine the effects of DL- $\alpha$ tocopherol supplementation on subclinical atherosclerosis progression in healthy low-risk individuals. They concluded that in well-nourished healthy vitamin E-replete individuals at low risk for CVD, vitamin $\mathrm{E}$ supplementation has no perceptible effect on the progression of atherosclerosis.

Other studies re-examined the preventive role of taking vitamin $\mathrm{E}$ or an inactive placebo for 3 years in men and women over the age of 40 years $^{(133,134)}$. Those taking vitamin $\mathrm{E}$ had the same amount of plaque build-up on their arteries as those taking placebo. The authors concluded that because the study lasted only 3 years, it cannot be ruled out that vitamin $\mathrm{E}$ might confer a protective effect in individuals taking it for a longer period of time. In addition, the vitamin $\mathrm{E}$ might be beneficial in individuals with kidney disease or diabetes, who are at increased risk for developing heart disease.

Another study found that in patients with vascular disease or diabetes mellitus, long-term vitamin E supplementation does not prevent cancer or major cardiovascular events and may increase the risk for heart failure ${ }^{(135)}$. Miller et al. ${ }^{(136)}$ performed a meta-analysis of the dose-response relationship between vitamin E supplementation and total mortality by using data from randomised, controlled trials. They found as limitations that high-dosage $(>400 \mathrm{IU} / \mathrm{d}$; $>267 \mathrm{mg} / \mathrm{d}$ ) trials were often small and were performed in patients with chronic diseases. Hence, the generalisability of the findings to healthy adults is uncertain. As conclusion, they affirm that high-dosage (>400 IU/d; $>267 \mathrm{mg} / \mathrm{d})$ vitamin E supplements may increase all-cause mortality and should be avoided.

Although some authors have agreed with previous findings of questionable effects of vitamin $\mathrm{E}$, other studies show a strong association between dietary vitamin $\mathrm{E}$ intake and risk of stroke, with a distinctive protective role in diabetes and atherosclerosis. In addition, the long-term effect of increasing vitamin $\mathrm{E}$ intake by using supplements remains to be determined. In general, studies on vitamin $\mathrm{E}$ and risk of stroke suggest that in women, dietary intake of vitamin $\mathrm{E}$ is protective, but the role of supplements remains contradictory and while some authors have reported some benefits, others were unable to confirm these results. However, vitamin E supplements may be of benefit to individuals at higher risk of stroke, due to high blood pressure or diabetes.

Vitamin C is capable of essentially influencing the course of many metabolic processes, and it is therefore used in the treatment and prophylaxis of many diseases, including processes associated with reactive oxygen species and oxidative stress. Therefore, because it appears that free radicals are relevant molecules associated with vascular pathologies, some studies have focused on the possibility of using vitamin $\mathrm{C}$ to lower or eliminate these molecules. In addition, vitamin $\mathrm{C}$ plays significant roles at the molecular level as a cofactor for several enzymes involved in the biosynthesis of collagen, carnitine and neurotransmitters. In fact, some studies have suggested the administration of vitamin $\mathrm{C}$ in the treatment of patients with coronary arterial disease, treatment of patients after cardiac infarction or cerebral stroke, or in the treatment of arterial hypertension ${ }^{(137)}$.

Plasma vitamin C concentration has also been found to be positively associated with cognitive function ${ }^{(138)}$. Vitamin C (ascorbic acid) is an extremely effective antioxidant that has been demonstrated to have potent antioxidant actions in human plasma and is associated with an $11 \%$ reduction in stroke prevalence ${ }^{(21,139,140)}$. Vitamin $C$ has been shown to significantly improve endothelium-dependent vasodilatation in diabetics and patients with coronary artery disease, perhaps by reducing excess superoxide production, and thereby decreasing the levels of NO inactivation ${ }^{(141)}$. Interestingly, there are no studies documenting the role that vitamin $\mathrm{C}$ may have in preventing stroke-mediated endothelial cell dysfunction. Antioxidant vitamins $\mathrm{E}$ and $\mathrm{C}$ may be capable of improving vascular function, quieting activated glial cells in the brain, and/or reducing the oxidative-mediated damage, which may be relevant to ameliorating or preventing the damage caused to neuron cells by circumscribed inflammatory processes ${ }^{(142-144)}$.

Although clinical trials have shown no significant benefit of vitamin $\mathrm{C}$ supplementation in reducing stroke risk, they were not able to examine the relationship between plasma vitamin $\mathrm{C}$ concentrations and stroke risk in a general population. Some studies have indicated that vitamin $\mathrm{C}$ may have some role in modulating hypertension, an important risk of stroke. A study by Kurl et al. ${ }^{(145)}$ examined whether plasma vitamin $\mathrm{C}$ modifies the association between overweight, hypertension and the risk of stroke in middleaged men from eastern Finland. Interestingly, low plasma vitamin $\mathrm{C}$ was associated with an increased risk of stroke, especially among hypertensive and overweight men. The recent study by Myint et al. ${ }^{(146)}$ examined the relationship between baseline plasma vitamin $\mathrm{C}$ concentrations and risk of incident stroke in a British population. The study was conducted in 20649 men and women aged 40-79 years without prevalent stroke at baseline and participating in the European Prospective Investigation into Cancer-Norfolk prospective population study. The participants completed a health questionnaire and attended a clinic between 1993 and 1997, and were followed up for incident strokes through to March 2005. This study concluded that plasma vitamin C concentrations may serve as a biological marker of lifestyle or other factors associated with reduced stroke risk and may be useful in identifying those at high risk of stroke.

Data regarding the effects of general nutritional status on stroke risk are limited. There is no evidence that the use of dietary vitamin $\mathrm{E}$ or $\mathrm{C}$ supplements or the use of specific carotenoids substantially reduces the risk of stroke ${ }^{(17)}$. An analysis of data from the Nurses' Health Study and the Health Professionals Follow-Up Study that included individuals free of CVD at baseline found that the relative risk of stroke was 0.69 (95\% CI 0.52, 0.92) for individuals in the highest quintile of fruit and vegetable intake ${ }^{(147)}$. 
An increment of one serving per d was associated with a $6 \%$ lower risk of stroke. However, it cannot be certain whether the effect was specifically due to diet or a reflection of a generally healthier lifestyle in these individuals.

On the other hand, it has been documented that there is a protective relationship between the consumption of green leafy vegetables, citrus fruit and juice, and ischaemic stroke risk ${ }^{(23,147)}$.

Randomised trials have largely failed to support an effect of antioxidant vitamins on the risk of CVD. Few trials have examined interactions among antioxidants. The Women's Antioxidant Cardiovascular Study tested the effects of ascorbic acid $(500 \mathrm{mg} / \mathrm{d})$, vitamin E (600 IU (400 mg) every other day) and $\beta$-carotene (50 mg every other day) on the combined outcome of myocardial infarction, stroke, coronary revascularisation, or CVD death among 8171 female health professionals at increased risk in a $2 \times 2 \times 2$ factorial design. Participants were aged 40 years or older with a history of CVD or three or more CVD risk factors and were followed up for a mean duration of 9.4 years, from 1995-6 to 2005. There were no significant interactions between agents for the primary end point, but those randomised to both active ascorbic acid and vitamin E experienced fewer strokes ${ }^{(148)}$

Ullegaddi et al. ${ }^{(149)}$ carried out a randomised controlled trial to test whether supplementary antioxidants immediately following acute ischaemic stroke will enhance antioxidant capacity and mitigate oxidative damage, concluding that supplementation with antioxidant vitamins (800 IU (727 mg) $\alpha$-tocopherol and $500 \mathrm{mg}$ vitamin $\mathrm{C}$ for $14 \mathrm{~d}$ ) within $12 \mathrm{~h}$ of onset of acute ischaemic stroke increased antioxidant capacity, reduced lipid peroxidation products and may have an anti-inflammatory effect. Therefore, it is very important to investigate the levels of vitamins $\mathrm{E}$ and $\mathrm{C}$ in relation to levels of cytokines, vascular alterations, and brain changes, and their association with cognition. The stroke-associated changes in brain vasculature, namely the development of metabolic and functional changes in the brain associated with impaired cognitive abilities, is caused by the development of an inflammatory response following stroke. Products of inflammatory reactions, such as cytokines, and adhesion molecules, therefore, may represent extracellular signals that initiate neuronal degeneration through several intracellular signals. Micronutrient deficiency will contribute, extending the cellular events to the cognitive impairment elicited by the ischaemic insult to the brain.

\section{Oxidative stress}

Oxidative stress in stroke patients has been discussed in many studies, but the results of these studies remain contradictory ${ }^{(49,150-157)}$. Experimental studies have provided evidence of an association between ischaemic stroke and increased oxidative stress. In fact, Cherubini et al. ${ }^{(158)}$ reported a significant reduction in several antioxidants immediately after an acute ischaemic stroke, possibly as a consequence of increased oxidative stress. A specific antioxidant profile is associated with a poor early outcome. Attention has recently focused on the measurement of $\mathrm{F}_{2}$-isoprostanes as a sensitive and specific index of oxidative stress. $\mathrm{F}_{2}$-isoprostanes are a family of eicosanoids of non-enzymic origin produced by the random oxidation of tissue phospholipids by oxygen radicals. Several reports have indicated that isoprostanes are elevated by oxidative stress. $\mathrm{F}_{2}$-isoprostanes have been proposed as markers of antioxidant deficiency and oxidative stress, and elevated levels have been reported in Alzheimer's disease and heavy smokers $^{(159,160)}$. Recently, the authors performed a casecontrol study of consecutive ischaemic stroke patients presenting within $8 \mathrm{~h}$ of stroke onset. In fifty-two cases and twenty-seven controls, early (median $6 \mathrm{~h}$ post-onset) $\mathrm{F}_{2}$ isoprostanes were elevated in stroke cases compared with controls and early plasma $\mathrm{F}_{2}$-isoprostanes correlated with metalloproteinase-9 in all patients $(P=0 \cdot 01)$. The study concluded that in early human stroke evidence has been found of increased oxidative stress and a relationship with metalloproteinase- 9 expression, supporting findings from experimental studies ${ }^{(161)}$. In another study, plasma levels of $\mathrm{F}_{2}$-isoprostanes were significantly elevated in the stroke patients compared with the control subjects $(P=0.02)^{(162)}$. Interestingly, in the study by Sánchez-Moreno et al. ${ }^{(162)}$ an inverse correlation between plasma vitamin $\mathrm{C}$ concentration and $\mathrm{F}_{2}$-isoprostane levels in the stroke patients, as well as a positive correlation between $\mathrm{C}$-reactive protein and $\mathrm{F}_{2^{-}}$ isoprostane levels were reported. This finding suggests that antioxidants may play a very important role in modulating the levels of inflammatory markers and consequently reduce the cognitive impairment changes associated with stroke.

Some epidemiological studies have reported on the effects of lipid peroxidation and antioxidant status on atherosclerosis and risk for stroke. In a recent study, serum levels of NO, malondialdehyde and glutathione were significantly elevated in acute stroke patients ${ }^{(163)}$. Other groups have evaluated this question by assessing the levels of thiobarbituric acid-reactive substances and analysed their relationship with antioxidant status and ultrasonographically assessed carotid atherosclerosis. A longitudinal study on cognitive and vascular ageing (Etude sur le Vieillisement Arteriel; the EVA Study), composed of 1187 men and women aged 59-71 years without any history of coronary artery disease or stroke, examined the intima-media thickness (IMT) on the common carotid arteries (CCA) and at the site of plaques ${ }^{(164)}$. After adjustment for conventional cardiovascular risk factors, erythrocyte vitamin E was significantly and negatively associated with CCA-IMT in both men and women. Interestingly, although no association was found between thiobarbituric acidreactive substances and CCA-IMT in either sex, thiobarbituric acid-reactive substances were significantly higher in men with carotid plaques than in those without ${ }^{(164)}$. Furthermore, this association was strengthened in men with concentrations of erythrocyte plasma vitamin E below the lowest quartile.

\section{Conclusions}

A large body of evidence suggests that intake of folate and B vitamins may be beneficial in stroke prevention by reducing levels of plasma Hcy; however, limited information is available regarding dietary intake of vitamins or use of 
vitamin supplements by stroke patients. Several studies are in progress to determine whether treatment with folic acid in combination with vitamins $\mathrm{B}_{6}$ and $\mathrm{B}_{12}$ will reduce the risk of stroke in patients with increased serum Hcy. Hcy is believed to cause atherogenesis and thrombogenesis via endothelial damage, focal vascular smooth muscle proliferation probably causing irregular vascular contraction, and coagulation abnormalities. Therefore, the significance of any association between CVD and stroke, and circulating Hcy concentrations is attracting considerable attention.

Antioxidant nutrients have important roles in cell function and have been implicated in processes associated with ageing, including vascular, inflammatory and neurological damage. Prospective studies that examined the association between vitamin $E$ intake and death from stroke have produced conflicting results. This is an important area of research that still remains poorly studied because in most of the studies there is no detailed information of the dose, frequency and time that these subjects were taking vitamin E supplements. In general, studies on vitamin $\mathrm{E}$ and risk of stroke suggest that in women, dietary intake of vitamin $\mathrm{E}$ is protective, but the role of supplements remains contradictory and while some authors have reported some benefits, others were unable to confirm these results. However, vitamin $\mathrm{E}$ supplements may be of benefit to individuals at higher risk of stroke, due to high blood pressure or diabetes. Plasma vitamin $\mathrm{C}$ concentration has also been found to be positively associated with cognitive function. Plasma vitamin $\mathrm{E}$ and $\mathrm{C}$ concentrations may serve as a biological marker of lifestyle or other factors associated with reduced stroke risk

As a general conclusion we can affirm that epidemiological associations and results of intervention studies suggest that low B vitamin status, elevated blood Hcy and low antioxidant status are risk factors for stroke. After reviewing the observational and intervention studies, there is an incomplete understanding of mechanisms and some conflicting findings; therefore the available evidence is insufficient to recommend the routine use of $\mathrm{B}$ vitamins, vitamin $\mathrm{E}$ and vitamin $\mathrm{C}$ for the prevention of stroke. A heart-healthy diet, emphasising fruits and vegetables containing B vitamins and antioxidants, may be the best recommendation. Further well-designed controlled clinical trials are necessary so that the detailed requirements of these individuals can be better understood.

\section{References}

1. Acheson RM \& Williams DR (1983) Does consumption of fruit and vegetables protect against stroke? Lancet i, 1191-1193.

2. Pohjasvaara T, Erkinjuntti T, Ylikoski R, et al. (1998) Clinical determinants of poststroke dementia. Stroke 29, 75-81.

3. Kase CS, Wolf PA, Kelly-Hayes M, et al. (1998) Intellectual decline after stroke: the Framingham Study. Stroke 29, $805-812$

4. Henon H, Lebert F, Durieu I, et al. (1999) Confusional state in stroke: relation to preexisting dementia, patient characteristics, and outcome. Stroke 30, 773-779.

5. Patel MD, Coshall C, Rudd AG, et al. (2002) Cognitive impairment after stroke: clinical determinants and its associations with long-term stroke outcomes. J Am Geriatr Soc 50, 700-706.

6. Gale CR, Martyn CN, Winter PD, et al. (1995) Vitamin C and risk of death from stroke and coronary heart disease in cohort of elderly people. Br Med J 310, 1563-1566.

7. Gale CR, Martyn CN \& Cooper C (1996) Cognitive impairment and mortality in a cohort of elderly people. $\mathrm{Br}$ Med J 312, 608-611.

8. Gonzalez-Gross M, Marcos A \& Pietrzik K (2001) Nutrition and cognitive impairment in the elderly. Br J Nutr 86, 313-321.

9. Singleton CK \& Martin PR (2001) Molecular mechanisms of thiamine utilization. Curr Mol Med 1, 197-207.

10. Mesnard F, Roscher A, Garlick AP, et al. (2002) Evidence for the involvement of tetrahydrofolate in the demethylation of nicotine by Nicotiana plumbaginifolia cell-suspension cultures. Planta 214, 911-919.

11. Nilsson K, Gustafson L \& Hultberg B (1999) Plasma homocysteine is a sensitive marker for tissue deficiency of both cobalamines and folates in a psychogeriatric population. Dement Geriatr Cogn Disord 10, 476-482.

12. Sarkar PK \& Lambert LA (2001) Aetiology and treatment of hyperhomocysteinaemia causing ischaemic stroke. Int $J$ Clin Pract 55, 262-268.

13. Miller JW, Green R, Mungas DM, et al. (2002) Homocysteine, vitamin $\mathrm{B}_{6}$, and vascular disease in $\mathrm{AD}$ patients. Neurology 58, 1471-1475.

14. Rogers PJ (2001) A healthy body, a healthy mind: long-term impact of diet on mood and cognitive function. Proc Nutr Soc 60, 135-143.

15. Robinson K (2000) Homocysteine, B vitamins, and risk of cardiovascular disease. Heart 83, 127-130.

16. Wang HX, Wahlin A, Basun H, et al. (2001) Vitamin $B_{12}$ and folate in relation to the development of Alzheimer's disease. Neurology 56, 1188-1194

17. Ascherio A, Rimm EB, Hernan MA, et al. (1999) Relation of consumption of vitamin $\mathrm{E}$, vitamin $\mathrm{C}$, and carotenoids to risk for stroke among men in the United States. Ann Int Med 130, 963-970.

18. Leppälä JM, Virtamo J, Fogelholm R, et al. (2000) Vitamin E and $\beta$ carotene supplementation in high risk for stroke: a subgroup analysis of the Alpha-Tocopherol, Beta-Carotene Cancer Prevention Study. Arch Neurol 57, 1503-1509.

19. Liu SM, Manson JE, Stampfer MJ, et al. (2000) Whole grain consumption and risk of ischemic stroke in women: a prospective study. JAMA 284, 1534-1540.

20. Ranjan A, Theodore D, Haran RP, et al. (1993) Ascorbic acid and focal cerebral ischaemia in a primate model. Acta Neurochir 123, 87-91.

21. Simon JA \& Hudes ES (1999) Serum ascorbic acid and cardiovascular disease prevalence in U.S. adults: the Third National Health and Nutrition Examination Survey (NHANES III). Ann Epidemiol 9, 358-365.

22. Feldman EB (2001) Fruits and vegetables and the risk of stroke. Nutr Rev 59, 24-27.

23. Gillman MW, Cupples AL, Gagnon D, et al. (1995) Protective effect of fruits and vegetables on development of stroke in men. JAMA 273, 1113-1117.

24. Yochum LA, Folsom AR \& Kushi LH (2000) Intake of antioxidant vitamins and risk of death from stroke in postmenopausal women. Am J Clin Nutr 72, 476-483.

25. Steiner M (1995) Vitamin E may enhance the benefits of aspirin in preventing stroke. Am Fam Physician 51, 1977.

26. Polasek J (1997) Acetylsalicylic acid and vitamin E in prevention of arterial thrombosis. Can J Cardiol 13, $533-535$. 
27. Pryor WA (2000) Vitamin E and heart disease: basic science to clinical intervention trials. Free Radic Biol Med 28, $141-164$.

28. Lauber RP \& Sheard NF (2001) The American Heart Association Dietary Guidelines for 2000: a summary report. Nutr Rev 59, 298-306.

29. Padro L, Benacer R, Foix S, et al. (2002) Assessment of dietary adequacy for an elderly population based on a Mediterranean model. J Nutr Health Aging 6, 31-33.

30. Klipstein-Grobusch K, den Breeijen JH, Grobbee DE, et al. (2001) Dietary antioxidants and peripheral arterial disease: the Rotterdam Study. Am J Epidemiol 154, 145-149.

31. Brussaard JH, Löwik MR, van den Berg H, et al. (1997) Folate intake and status among adults in the Netherlands. Eur J Clin Nutr 51, S46-S50.

32. de Bree A, Verschuren WMM, Blom HJ, et al. (2001) Association between B vitamin intake and plasma homocysteine concentration in the general Dutch population aged 20-65 y. Am J Clin Nutr 73, 1027-1033.

33. Kelly PJ \& Furie KL (2002) Management and prevention of stroke associated with elevated homocysteine. Curr Treat Options Cardiovasc Med 4, 363-371.

34. Liaugaudas G, Jacques PF, Selhub J, et al. (2001) Renal insufficiency, vitamin $\mathrm{B}_{12}$ status, and population attributable risk for mild hyperhomocysteinemia among coronary artery disease patients in the era of folic acid-fortified cereal grain flour. Arterioscler Thromb Vasc Biol 21, 849-851.

35. Green R \& Miller JW (2005) Vitamin $B_{12}$ deficiency is the dominant nutritional cause of hyperhomocysteinemia in a folic acid-fortified population. Clin Chem Lab Med 43, 1048-1051.

36. Howard VJ, Sides EG, Newman GC, et al. (2002) Changes in plasma homocyst(e)ine in the acute phase after stroke. Stroke 33, 473-478.

37. Mezzano D, Pais EO, Aranda E, et al. (2001) Inflammation, not hyperhomocysteinemia, is related to oxidative stress and hemostatic and endothelial dysfunction in uremia. Kidney Int 60, 1844-1850.

38. Strazzullo P, Scalfi L, Branca E, et al. (2004) Nutrition and prevention of ischemic stroke: present knowledge, limitations and future perspectives. Nutr Metab Cardiovasc Dis 14, 97-114.

39. Spence JD (2003) Nutritional and metabolic aspects of stroke prevention. Adv Neurol 92, 173-178.

40. Gariballa SE (2000) Nutritional factors in stroke. Br J Nutr 84, 5-17.

41. Gariballa SE (2000) Nutritional support in elderly patients. $J$ Nutr Health Aging 4, 25-27.

42. Renaud SC (2001) Diet and stroke. J Nutr Health Aging 5, $167-172$.

43. Gariballa SE, Parker SG, Taub N, et al. (1998) Influence of nutritional status on clinical outcome after acute stroke. Am J Clin Nutr 68, 275-281.

44. Gariballa SE, Parker SG, Taub N, et al. (1998) Nutritional status of hospitalized acute stroke patients. Br J Nutr 79, 481-487.

45. Elmståhl S, Bülow M, Ekberg O, et al. (1999) Treatment of dysphagia improves nutritional conditions in stroke patients. Dysphagia 14, 61-66.

46. Dennis M (2000) Nutrition after stroke. Br Med Bull 56, 466-475.

47. Westergren A, Karlsson S, Andersson P, et al. (2001) Eating difficulties, need for assisted eating, nutritional status and pressure ulcers in patients admitted for stroke rehabilitation. J Clin Nurs 10, 257-269.

48. Westergren A, Ohlsson O \& Hallberg IR (2001) Eating difficulties, complications and nursing interventions during a period of three months after a stroke. $J$ Adv Nurs $\mathbf{3 5}$, 416-426.

49. Deschamps V, Barberger-Gateau P, Peuchant E, et al. (2001) Nutritional factors in cerebral aging and dementia: epidemiological arguments for a role of oxidative stress. Neuroepidemiology 20, 7-15.

50. Spence JD (2006) Nutrition and stroke prevention. Stroke 37, 2430-2435.

51. Van Duyn MA \& Pivonka E (2000) Overview of the health benefits of fruit and vegetable consumption for the dietetics professional: selected literature. J Am Diet Assoc 100, $1511-1521$.

52. Bazzano LA, He J, Ogden LG, et al. (2002) Fruit and vegetable intake and risk of cardiovascular disease in US adults: the first National Health and Nutrition Examination Survey Epidemiologic Follow-up Study. Am J Clin Nutr 76, 93-99.

53. Gillman MW, Cupples LA, Millen BE, et al. (1997) Inverse association of dietary fat with development of ischemic stroke in men. JAMA 278, 2145-2150.

54. Iso H, Rexrode KM, Stampfer MJ, et al. (2001) Intake of fish and omega-3 fatty acids and risk of stroke in women. JAMA 285, 304-312.

55. Zhang J, Sasaki S, Amano K, et al. (1999) Fish consumption and mortality from all causes, ischemic heart disease, and stroke: an ecological study. Prev Med 28, 520-529.

56. Molloy AM, Mills JL, Kirke PN, et al. (1999) Folate status and neural tube defects. Biofactors 10, 291-294.

57. Selhub J, Bagley LC, Miller J, et al. (2000) B vitamins, homocysteine, and neurocognitive function in the elderly. Am J Clin Nutr 71, 614S-620S.

58. Rosenberg IH (2001) B vitamins, homocysteine, and neurocognitive function. Nutr Rev 59, S69-S73.

59. Balk EM, Raman G, Tatsioni A, et al. (2007) Vitamin $B_{6}$, $\mathrm{B}_{12}$, and folic acid supplementation and cognitive function: a systematic review of randomized trials. Arch Intern Med 167, 21-30.

60. Robinson K, Arheart K, Refsum H, et al. (1998) Low circulating folate and vitamin $\mathrm{B}_{6}$ concentrations: risk factors for stroke, peripheral vascular disease, and coronary artery disease. Circulation 97, 437-443.

61. Troen A \& Rosenberg I (2005) Homocysteine and cognitive function. Semin Vasc Med 5, 209-214.

62. Clarke R (2008) B vitamins and prevention of dementia. Proc Nutr Soc 67, 75-81.

63. Bazzano LA, He J, Ogden LG, et al. (2002) Dietary intake of folate and risk of stroke in US men and women: NHANES I Epidemiologic Follow-up Study. National Health and Nutrition Examination Survey. Stroke 33, $1183-1189$.

64. Albert CM, Cook NR, Gaziano JM, et al. (2008) Effect of folic acid and B vitamins on risk of cardiovascular events and total mortality among women at high risk for cardiovascular disease: a randomized trial. JAMA 299, 2027-2036.

65. Lonn E, Yusuf S, Arnold MJ, et al. (2006) Homocysteine lowering with folic acid and B vitamins in vascular disease. N Engl J Med 354, 1567-1577.

66. Bønaa KH, Njølstad I, Ueland PM, et al. (2006) Homocysteine lowering and cardiovascular events after acute myocardial infarction. $N$ Engl J Med 354, $1578-1588$.

67. Beamer NB, Coull BM, Press RD, et al. (1999) Vitamin use in patients with ischemic stroke. Neurology 52, A64.

68. VITATOPS Trial Study Group (2002) The VITATOPS (Vitamins to Prevent Stroke) Trial: rationale and design of an international, large, simple, randomised trial of 
homocysteine-lowering multivitamin therapy in patients with recent transient ischaemic attack or stroke. Cerebrovasc Dis 13, 120-126.

69. Spence JD, Howard VJ, Chambless LE, et al. (2001) Vitamin Intervention for Stroke Prevention (VISP) Trial: rationale and design. Neuroepidemiology 20, 16-25.

70. Toole JF, Malinow MR, Chambless LE, et al. (2004) Lowering homocysteine in patients with ischemic stroke to prevent recurrent stroke, myocardial infarction and death. The Vitamin Intervention for Stroke Prevention (VISP) randomized controlled trial. JAMA 291, 565-575.

71. Hankey GJ \& Eikelboom JW (2004) Folic acid-based multivitamin therapy to prevent stroke: the jury is still out. Stroke 35, 1995-1998.

72. Wald DS, Law M \& Morris JK (2002) Homocysteine and cardiovascular disease: evidence on causality from a metaanalysis. Br Med J 325, 1202-1208.

73. He K, Merchant A, Rimm EB, et al. (2004) Folate, vitamin $\mathrm{B}_{6}$, and $\mathrm{B}_{12}$ intakes in relation to risk of stroke among men. Stroke 35, 169-174.

74. Clarke R \& Armitage J (2000) Vitamin supplements and cardiovascular risk: review of the randomized trials of homocysteine-lowering vitamin supplements. Semin Thromb Hemost 26, 341-348.

75. Yang Q, Botto LD, Erickson JD, et al. (2006) Improvement in stroke mortality in Canada and the United States, 1990 to 2002. Circulation 113, 1335-1343.

76. Goldstein LB (2000) Novel risk factors for stroke: homocysteine, inflammation, and infection. Curr Atheroscler Rep 2, 110-114.

77. Perry IJ (1999) Homocysteine, hypertension and stroke. J Hum Hypertens 13, 289-293.

78. Perry IJ (1999) Homocysteine and risk of stroke. $J$ Cardiovasc Risk 6, 235-240.

79. Hankey GJ (2002) Is homocysteine a causal and treatable risk factor for vascular diseases of the brain (cognitive impairment and stroke)? Ann Neurol 51, 279-281.

80. Christopher R, Nagaraja D \& Shankar SK (2007) Homocysteine and cerebral stroke in developing countries. Curr Med Chem 14, 2393-2401.

81. McNulty H, Pentieva K, Hoey L, et al. (2008) Homocysteine, B vitamins and CVD. Proc Nutr Soc 67, 232-237.

82. Cui RZ, Moriyama Y, Koike KA, et al. (2008) Serum total homocysteine concentrations and risk of mortality from stroke and coronary heart disease in Japanese: the JACC study. Atherosclerosis 198, 412-418.

83. Ntaios GC, Savopoulos CG, Chatzinikolaou AC, et al. (2008) Vitamins and stroke: the homocysteine hypothesis still in doubt. Neurologist 14, 2-4.

84. Clarke R, Armitage J, Lewington S, et al. (2007) Homocysteine-lowering trials for prevention of vascular disease: protocol for a collaborative meta-analysis. Clin Chem Lab Med 45, 1575-1581.

85. Carlsson CM (2007) Lowering homocysteine for stroke prevention. Lancet 369, 1841-1842.

86. Spence JD (2006) Homocysteine and stroke prevention: have the trials settled the issue? Int J Stroke 1, 242-244.

87. Loscalzo J (2006) Homocysteine trials - clear outcomes for complex reasons. $N$ Engl J Med 354, 1629-1632.

88. Herrmann W (2001) The importance of hyperhomocysteinemia as a risk factor for diseases: an overview. Clin Chem Lab Med 39, 666-674.

89. Morris MS, Jacques PF, Rosenberg IH, et al. (2000) Serum total homocysteine concentration is related to self-reported heart attack or stroke history among men and women in the NHANES III. $J$ Nutr 130, 3073-3076.
90. Kuller LH \& Evans RW (1998) Homocysteine, vitamins, and cardiovascular disease. Circulation 98, 196-199.

91. Giles WH, Croft JB, Greenlund KJ, et al. (1998) Total homocyst(e)ine concentration and the likelihood of nonfatal stroke: results from the Third National Health and Nutrition Examination Survey, 1988-1994. Stroke 29, 2473-2477.

92. Perry IJ, Refsum H, Morris RW, et al. (1995) Prospective study of serum total homocysteine concentration and risk of stroke in middle-aged British men. Lancet 346, 1395-1398.

93. Verhoef P, Hennekens CH, Malinow MR, et al. (1994) A prospective study of plasma homocyst(e)ine and risk of ischemic stroke. Stroke 25, 1924-1930.

94. Fallon UB, Elwood P, Ben-Shlomo Y, et al. (2001) Homocysteine and ischaemic stroke in men: the Caerphilly study. J Epidemiol Community Health 55, 91-96.

95. Bots ML, Launer LJ, Lindemans J, et al. (1999) Homocysteine and short-term risk of myocardial infarction and stroke in the elderly: the Rotterdam Study. Arch Intern Med 159, 38-44.

96. Fridman O (1999) Hyperhomocysteinemia: atherothrombosis and neurotoxicity. Acta Physiol Pharmacol Ther Latinoam 49, 21-30.

97. Mayer EL, Jacobsen DW \& Robinson K (1996) Homocysteine and coronary atherosclerosis. J Am Coll Cardiol 27, 517-527.

98. Mutus B, Rabini RA, Staffolani R, et al. (2001) Homocysteine-induced inhibition of nitric oxide production in platelets: a study on healthy and diabetic subjects. Diabetologia 44, 979-982.

99. Durand P, Lussier-Cacan S \& Blache D (1997) Acute methionine load-induced hyperhomocysteinemia enhances platelet aggregation, thromboxane biosynthesis, and macrophage-derived tissue factor activity in rats. FASEB $J \mathbf{1 1}$, 1157-1168.

100. Prasad K (1999) Homocysteine, a risk factor for cardiovascular disease. Int J Angiology 8, 76-86.

101. Coppola A, Davi G, De Stefano V, et al. (2000) Homocysteine, coagulation, platelet function, and thrombosis. Semin Thromb Hemost 26, 243-254.

102. Zhang G, Zhao $\mathrm{H}$ \& Zhang L (1999) Effects of homocysteine on human vascular endothelial cells, platelet aggregation and heparin cofactor activity (article in Chinese). Zhonghua Xue Ye Xue Za Zhi 20, 471-473.

103. Hladovec J, Sommerova Z \& Pisarikova A (1997) Homocysteinemia and endothelial damage after methionine load. Thromb Res 88, 361-364.

104. Domagala TB, Undas A, Libura M, et al. (1998) Pathogenesis of vascular disease in hyperhomocysteinaemia. J Cardiovasc Risk 5, 239-247.

105. Zhang C, Cai Y, Adachi MT, et al. (2001) Homocysteine induces programmed cell death in human vascular endothelial cells through activation of the unfolded protein response. J Biol Chem 276, 35867-35874.

106. Mercié P, Garnier O, Lascoste L, et al. (2000) Homocysteine-thiolactone induces caspase-independent vascular endothelial cell death with apoptotic features. Apoptosis $\mathbf{5}$, 403-411.

107. Wang H, Yoshizumi M, Lai KH, et al. (1997) Inhibition of growth and p21ras methylation in vascular endothelial cells by homocysteine but not cysteine. J Biol Chem 272, 25380-25385.

108. Chambers JC, McGregor A, Jean-Marie J, et al. (1999) Demonstration of rapid onset vascular endothelial dysfunction after hyperhomocysteinemia: an effect reversible with vitamin C therapy. Circulation 99, 1156-1160.

109. Li H, Lewis A, Brodsky S, et al. (2002) Homocysteine induces 3-hydroxy-3-methylglutaryl coenzyme A reductase 
in vascular endothelial cells: a mechanism for development of atherosclerosis? Circulation 105, 1037-1043.

110. Kokame K, Kato H \& Miyata T (1998) Nonradioactive differential display cloning of genes induced by homocysteine in vascular endothelial cells. Methods 16, 434-443.

111. SoRelle R (2002) Inflammation-sensitive proteins: another ingredient in stroke? Circulation 105, e9111.

112. Outinen PA, Sood SK, Pfeifer SI, et al. (1999) Homocysteine-induced endoplasmic reticulum stress and growth arrest leads to specific changes in gene expression in human vascular endothelial cells. Blood 94, 959-967.

113. Cai Y, Zhang C, Nawa T, et al. (2000) Homocysteineresponsive ATF3 gene expression in human vascular endothelial cells: activation of c-Jun NH(2)-terminal kinase and promoter response element. Blood 96, 2140-2148.

114. Poddar R, Sivasubramanian N, DiBello PM, et al. (2001) Homocysteine induces expression and secretion of monocyte chemoattractant protein-1 and interleukin- 8 in human aortic endothelial cells: implications for vascular disease. Circulation 103, 2717-2723.

115. Holven KB, Aukrust P, Holm T, et al. (2002) Folic acid treatment reduces chemokine release from peripheral blood mononuclear cells in hyperhomocysteinemic subjects. Arterioscler Thromb Vasc Biol 22, 699-703.

116. Wang G, Siow YL \& O K (2001) Homocysteine induces monocyte chemoattractant protein-1 expression by activating NF-кB in THP-1 macrophages. Am J Physiol Heart Circ Physiol 280, H2840-H2847.

117. Desai A, Lankford HA \& Warren JS (2001) Homocysteine augments cytokine-induced chemokine expression in human vascular smooth muscle cells: implications for atherogenesis. Inflammation 25, 179-186.

118. Roth J, Goebeler M, Ludwig S, et al. (2001) Homocysteine inhibits tumor necrosis factor-induced activation of endothelium via modulation of nuclear factor- $\mathrm{\kappa} B$ activity. Biochim Biophys Acta 1540, 154-165.

119. Cherubini A, Ruggiero C, Morand C, et al. (2008) Dietary antioxidants as potential pharmacological agents for ischemic stroke. Curr Med Chem 15, 1236-1248.

120. Moats C \& Rimm EB (2007) Vitamin intake and risk of coronary disease: observation versus intervention. Curr Atheroscler Rep 9, 508-514.

121. Thomas DR (2006) Vitamins in aging, health, and longevity. Clin Intervent Aging 1, 81-91.

122. Arria AM, Tarter RE, Warty V, et al. (1990) Vitamin E deficiency and psychomotor dysfunction in adults with primary biliary cirrhosis. Am J Clin Nutr 52, 383-390.

123. Shorer Z, Parvari R, Bril G, et al. (1996) Ataxia with isolated vitamin E deficiency in four siblings. Pediatr Neurol 15, 340-343.

124. Behl C (1999) Vitamin E and other antioxidants in neuroprotection. Int J Vitam Nutr Res 69, 213-219.

125. Launer LJ \& Kalmijn S (1998) Anti-oxidants and cognitive function: a review of clinical and epidemiologic studies. $J$ Neural Transm Suppl 53, 1-8.

126. Perkins AJ, Hendrie HC, Callahan CM, et al. (1999) Association of antioxidants with memory in a multiethnic elderly sample using the Third National Health and Nutrition Examination Survey. Am J Epidemiol 150, 37-44.

127. Schmidt R, Hayn M, Reinhart B, et al. (1998) Plasma antioxidants and cognitive performance in middle-aged and older adults: results of the Austrian Stroke Prevention study. J Am Geriatr Soc 46, 1407-1410.

128. Rosenblum WI, Nelson GH, Bei RA, et al. (1996) Vitamin E ameliorates adverse effects of endothelial injury in brain arterioles. Am J Physiol Heart Circul Physiol 40, H637-H642.

129. Leppälä JM, Virtamo J, Fogelholm R, et al. (2000) Controlled trial of $\alpha$-tocopherol and $\beta$-carotene supplements on stroke incidence and mortality in male smokers. Arterioscler Thromb Vasc Biol 20, 230-235.

130. Benson RT (1999) Vitamin E supplementation lowers risk for ischemic stroke. 51st Annual Meeting of the American Academy of Neurology. Toronto, Canada.

131. Devaraj S \& Jialal I (2000) $\alpha$ Tocopherol supplementation decreases serum C-reactive protein and monocyte interleukin-6 levels in normal volunteers and type 2 diabetic patients. Free Radic Biol Med 29, 790-792.

132. Hodis HN, Mack WJ, LaBree LD, et al. (2002) $\alpha$-Tocopherol supplementation in healthy individuals reduces low-density lipoprotein oxidation but not atherosclerosis: the Vitamin E Atherosclerosis Prevention Study (VEAPS). Circulation 106, 1453-1459.

133. Bunout D (2000) Therapeutic potential of vitamin $E$ in heart disease. Expert Opin Investig Drugs 9, 2629-2635.

134. Dagenais GR, Marchioli R, Yusuf S, et al. (2000) $\beta$-Carotene, vitamin $\mathrm{C}$, and vitamin $\mathrm{E}$ and cardiovascular diseases. Curr Cardiol Rep 2, 293-299.

135. Lonn E (2005) Effects of long-term vitamin E supplementation on cardiovascular events and cancer: a randomized controlled trial. JAMA 293, 1338-1347.

136. Miller ER III, Pastor-Barriuso R, Dalal D, et al. (2005) Meta-analysis: high-dosage vitamin E supplementation may increase all-cause mortality. Ann Inter Med 142, 37-46.

137. Grzegorczyk K, Rutkowski M \& Drozda R (2001) Vitamin C in treatment of certain cardiovascular diseases. Pol Merkur Lekarski 10, 122-125.

138. Foy CJ, Passmore AP, Vahidassr MD, et al. (1999) Plasma chain-breaking antioxidants in Alzheimer's disease, vascular dementia and Parkinson's disease. Q J Med 92, 39-45.

139. Frei, B. (ed.). (1994) Natural Antioxidants in Human Health and Disease. San Diego, CA: Academic Press.

140. Simon JA, Hudes ES \& Browner WS (1998) Serum ascorbic acid and cardiovascular disease prevalence in U.S. adults. Epidemiolology 9, 316-321.

141. Ness AR, Powles JW \& Khaw KT (1996) Vitamin C and cardiovascular disease: a systematic review. J Cardiovasc Risk 3, 513-521.

142. Sano M, Ernesto C, Thomas RG, et al. (1997) A controlled trial of selegiline, $\alpha$-tocopherol, or both as treatment for Alzheimer's disease. $N$ Engl J Med 336, 1216-1222.

143. Padh H (1991) Vitamin C: newer insights into its biochemical functions. Nutr Rev 49, 65-70.

144. Sato K, Saito H \& Katsuki H (1993) Synergism of tocopherol and ascorbate on the survival of cultured brain neurones. Neuroreport 4, 1179-1182.

145. Kurl S, Tuomainen TP, Laukkanen JA, et al. (2002) Plasma vitamin $\mathrm{C}$ modifies the association between hypertension and risk of stroke. Stroke 33, 1568-1573.

146. Myint PK, Luben RN, Welch AA, et al. (2008) Plasma vitamin $\mathrm{C}$ concentrations predict risk of incident stroke over $10 \mathrm{y}$ in 20649 participants of the European Prospective Investigation into Cancer-Norfolk prospective population study. Am J Clin Nutr 87, 64-69.

147. Joshipura KJ, Ascherio A, Manson JE, et al. (1999) Fruit and vegetable intake in relation to risk of ischemic stroke. JAMA 282, 1233-1239.

148. Cook NR, Albert CM, Gaziano JM, et al. (2007) A randomized factorial trial of vitamins $\mathrm{C}$ and $\mathrm{E}$ and $\beta$ carotene in the secondary prevention of cardiovascular events in women: results from the Women's Antioxidant Cardiovascular Study. Arch Int Med 167, 1610-1618. 
149. Ullegaddi R, Powers HJ \& Gariballa SE (2005) Antioxidant supplementation enhances antioxidant capacity and mitigates oxidative damage following acute ischaemic stroke. Eur J Clin Nutr 59, 1367-1373.

150. Ungvari Z, Buffenstein R, Austad SN, et al. (2008) Oxidative stress in vascular senescence: lessons from successfully aging species. Front Biosci 13, 5056-5070.

151. Allen CL \& Bayraktutan U (2008) Risk factors for ischaemic stroke. Int J Stroke 3, 105-116.

152. Taffi R, Nanetti L, Mazzanti L, et al. (2008) Plasma levels of nitric oxide and stroke outcome. J Neurol 255, 94-98.

153. Ferretti G, Bacchetti T, Masciangelo S, et al. (2008) Lipid peroxidation in stroke patients. Clin Chem Lab Med 46, $113-117$

154. Seneş M, Kazan N, Coşkun Ö, et al. (2007) Oxidative and nitrosative stress in acute ischaemic stroke. Ann Clin Biochem 44, 43-47.

155. Mariani E, Polidori MC, Cherubini A, et al. (2005) Oxidative stress in brain aging, neurodegenerative and vascular diseases: an overview. $J$ Chromatogr B 827, $65-75$.

156. Cherubini A, Ruggiero C, Polidori MC, et al. (2005) Potential markers of oxidative stress in stroke. Free Radic Biol Med 39, 841-852.

157. Polidori MC, Frei B, Cherubini A, et al. (1998) Increased plasma levels of lipid hydroperoxides in patients with ischemic stroke. Free Radic Biol Med 25, 561-567.

158. Cherubini A, Polidori MC, Bregnocchi M, et al. (2000) Antioxidant profile and early outcome in stroke patients. Stroke 31, 2295-2300.

159. Pratico D, Lee VMY, Trojanowski JQ, et al. (1998) Increased $\mathrm{F}_{2}$-isoprostanes in Alzheimer's disease: evidence for enhanced lipid peroxidation in vivo. FASEB $J \mathbf{1 2}$, 1777-1783.

160. May JM, Qu ZC, Morrow JD, et al. (2000) Ascorbatedependent protection of human erythrocytes against oxidant stress generated by extracellular diazobenzene sulfonate. Biochem Pharmacol 60, 47-53.

161. Kelly PJ, Morrow JD, Ning M, et al. (2008) Oxidative stress and matrix metalloproteinase-9 in acute ischemic stroke: The Biomarker Evaluation for Antioxidant Therapies in Stroke (BEAT-Stroke) study. Stroke 39, 100-104.

162. Sánchez-Moreno C, Dashe JF, Scott T, et al. (2004) Decreased levels of plasma vitamin $\mathrm{C}$ and increased concentrations of inflammatory and oxidative stress markers after stroke. Stroke 35, 163-168.

163. Ozkul A, Akyol A, Yenisey C, et al. (2007) Oxidative stress in acute ischemic stroke. J Clin Neurosci 14, 1062-1066.

164. Bonithon-Kopp C, Coudray C, Berr C, et al. (1997) Combined effects of lipid peroxidation and antioxidant status on carotid atherosclerosis in a population aged 59-71 y: The EVA Study. Etude sur le Vieillisement Arteriel. Am J Clin Nutr 65, 121-127.

165. Yoo JH \& Lee SC (2001) Elevated levels of plasma homocyst(e)ine and asymmetric dimethylarginine in elderly patients with stroke. Atherosclerosis 158, 425-430.

166. Iso H (2005) Homocysteine and increased risk of stroke. Cardiol Rev 22, 26-29.

167. Keli SO, Hertog MG, Feskens EJ, et al. (1996) Dietary flavonoids, antioxidant vitamins, and incidence of stroke: the Zutphen study. Arch Intern Med 156, 637-642.

168. Daviglus ML, Orencia AJ, Dyer AR, et al. (1997) Dietary vitamin $\mathrm{C}, \beta$-carotene and 30-year risk of stroke: results from the Western Electric Study. Neuroepidemiology 16, $69-77$.

169. Hirvonen T, Virtamo J, Korhonen P, et al. (2000) Intake of flavonoids, carotenoids, vitamins $\mathrm{C}$ and $\mathrm{E}$, and risk of stroke in male smokers. Stroke 31, 2301-2306.

170. Yokoyama T, Date C, Kokubo Y, et al. (2000) Serum vitamin $\mathrm{C}$ concentration was inversely associated with subsequent 20-year incidence of stroke in a Japanese rural community. The Shibata study. Stroke 31, 2287-2294.

171. Polidori MC, Mecocci P \& Frei B (2001) Plasma vitamin C levels are decreased and correlated with brain damage in patients with intracranial hemorrhage or head trauma. Stroke 32, 898-902.

172. Vokó Z, Hollander M, Hofman A, et al. (2003) Dietary antioxidants and the risk of ischemic stroke: The Rotterdam Study. Neurology 61, 1273-1275.

173. Benson RT, Jacobs B, Boden-Albala B, et al. (1999) Vitamin E intake: a primary preventive measure in stroke. Neurology 52, A146.

174. Vatassery GT, Bauer T \& Dysken M (1999) High doses of vitamin $\mathrm{E}$ in the treatment of disorders of the central nervous system in the aged. Am J Clin Nutr 70, 793-801.

175. Suter PM (2000) Effect of vitamin E, vitamin C, and $\beta$-carotene on stroke risk. Nutr Rev 58, 184-187. 